\title{
Truncated Tyrosine Kinase Receptor B (TrkB.T1) plays a role in susceptibility to chronic stress
}

\author{
by
}

Sara Khalaf

A thesis submitted to the Faculty of Graduate and Postdoctoral Affairs in partial fulfillment of the requirements for the degree of

Master of Science

in

Neuroscience

Carleton University

Ottawa, Ontario

(C) 2020, Sara Khalaf 


\section{Acknowledgments}

There are multiple people that played a major role in helping me succeed and achieve this thesis. I honestly don't think I would have been able to do it without their great support!

To begin, I would like to sincerely thank my supervisor, Dr. Shawn Hayley, for always being there for me and guiding me through everything. His support throughout this process was incredible and so was his attitude towards everything! His strong belief in me is what made me want to work harder. Additionally, I would like to thank my committee members, Dr. Patrice Smith, Dr. Argel Aguilar Valles, and Dr. William Willmore for being supportive and making the prospectus and defense presentations fun rather than stressful!

Special thanks to Dr. Hymie Anisman for his great wisdom and his great sense of humor! He is so dear to me as I see him as my grandfather! I truly wish him nothing but the ultimate best.

To our lab manager, Teresa Fortin, you will always be my Mama Teresa! I will miss your laugh so much as it always brightened my day! Of course, I would like to also thank Natalie Prowse for working with me in this project as she was a great partner-in-crime.

Lastly, thank you my dear family for your amazing support! Baba, Mama, I love you both so much! Tristan, you're my rock! Thank you so much for being super supportive and awesome. I wouldn't have been able to do it without the love and support of my amazingly large family! 


\section{Table of Contents}

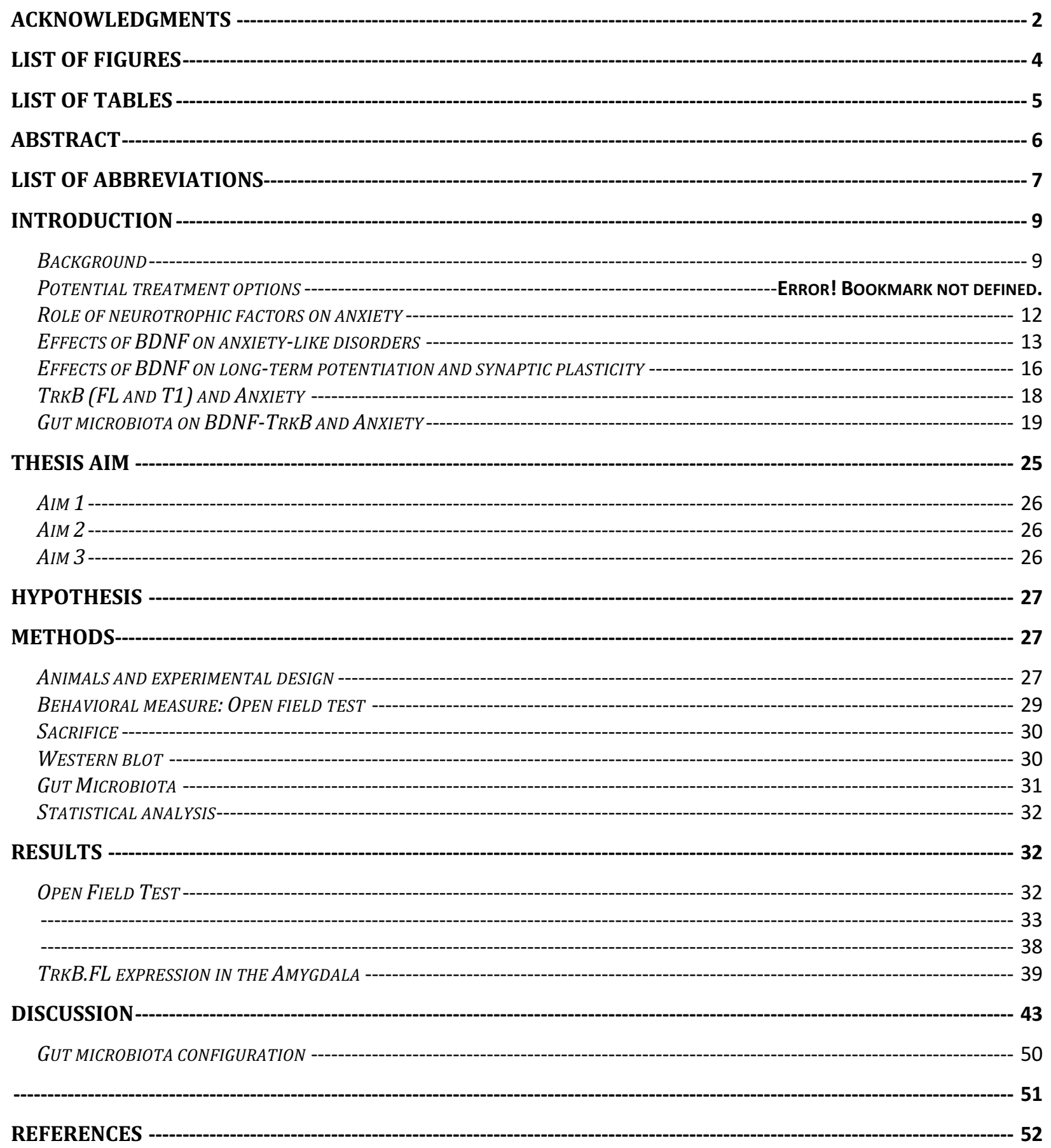




\section{List of Figures}

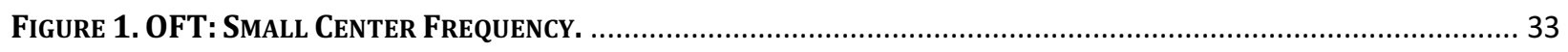

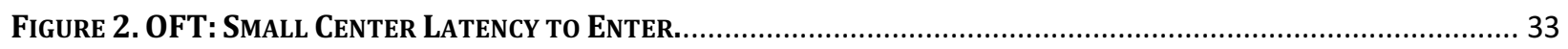

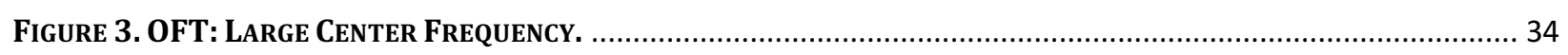

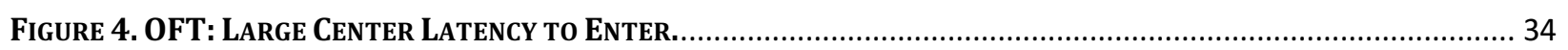

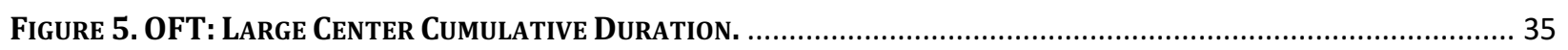

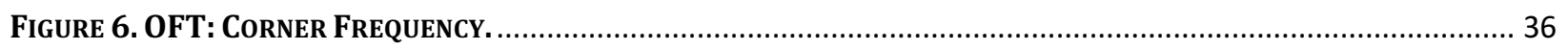

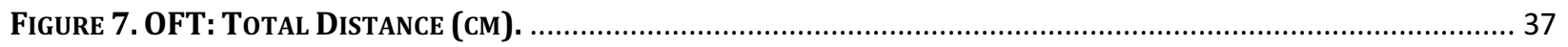

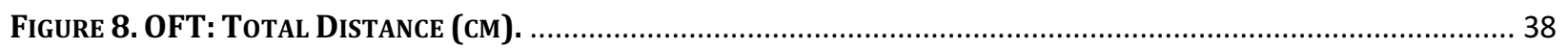

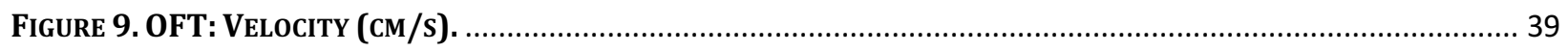

FigURE 10. FULLY GLYCoSYLATED TRKB.FL BY SEX AND TREATMENT. ................................................................ 40

Figure 11. Partially glycosylated TrkB.FL by SeX and Treatment......................................................... 41

FIGURE 12. WESTERN BLOT OF TRKB.FL (BD610101 ANTIBODY). .................................................................. 41

FIGURE 13. RATIO OF FULLY GLYCoSYLATED P.TRKB.FL AND TRKB.FL BY SEX AND TREATMENT................................. 41

Figure 14. RATIO OF PARTIALLY GLYCosylated PTRKB.FL AND TRKB.FL by SEX AND TREATMENT. ......................... 42

Figure 15. Ratio of PARTially GLyCosylated PTRKB.FL and TRKB.FL by TREATMENT, GENotyPE AND SEX. ........ 42

FIGURE 16. RATIO OF FULLY GLYCoSYLATED PTRKB.FL AND TRKB.FL BY TREATMENT, GENOTYPE AND SEX.................. 43

FigURE 17. WESTERN BLOT OF UNPHOSPHORYLATED TRKB.FL (LEFT IMAGE - 1:1000BD610101 RABBIT ANTIBODY) AND Phosphorylated TrkB.FL (RIGHT IMAGE - 1:1000 ABN1381 MouSE)............................................ 43

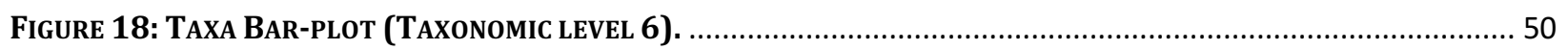

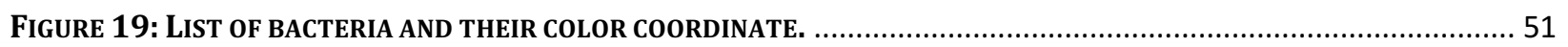




\section{List of Tables}

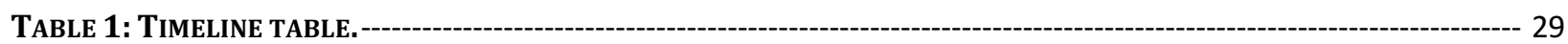

TABLE 2: CHRONIC UNPREDICTABLE STRESS SCHEDULE: --- 29 


\section{Abstract}

Brain-derived neurotrophic factor (BDNF) and its receptor, tyrosine kinase B (TrkB), have been implicated in depressive and anxiety disorders. In fact, the efficacy of antidepressant agents may be related to BDNF-TrkB signaling fueling important neuroplastic changes. Interestingly, besides the full-length version of $\operatorname{TrkB}$, the receptor can also be alternatively processed into a truncated form, TrkB.T1, which can act in an inhibitory capacity. However, there is reason to believe that TrkB.T1 might also have other novel signaling effects that might be relevant for dealing with stressors. To this end, using mice lacking TrkB.T1 and wild type littermates exposed to a chronic stressor regimen, we assessed behavioral and TrkB expression profiles, as well as gut microbial profile (given its recent links with anxiety). Our results showed that while the repeated different stressor regimen did markedly alter open-field performance, this was unaffected by the TrkB.T1 knockout. A sex effect was apparent, however in that male mice showed the greatest exploration abnormalities. Moreover, TrkB expression within the amygdala also varied as a function of sex; yet, there were no observed difference in the gut microbiota among the groups. These data do not support a major role for TrkB.T1 in modulating anxiety phenotype, but there were many limitations of this thesis study. Further experiments will focus more comprehensively upon the phenotype of TrkB.T1 mice, particularly with regards to depressive-like pathology. 


\section{List of Abbreviations}

\begin{tabular}{|l|l|}
\hline $5-H T$ & Serotonin \\
\hline ACTH & Adrenocorticotropic hormone \\
\hline ANOVA & Analysis of variance \\
\hline AVP & Arginine-vasopressin \\
\hline BDNF & Brain derived neurotrophic factor \\
\hline BLA & Basolateral amygdala \\
\hline BOLD & Blood-oxygen-level-dependent \\
\hline Brd-U & Bromodeoxyuridine / 5-bromo-2'-deoxyuridine \\
\hline Ca2+ & Calcium \\
\hline CAMP & Cyclic adenosine monophosphate \\
\hline CBT & Cognitive behavioural therapy \\
\hline CeA & Central nucleus of the amygdala \\
\hline CORT & corticosterone \\
\hline CREB & cAMP response element-binding protein \\
\hline CRH & Corticotrophin releasing hormone \\
\hline CUS & Chronic unpredictable stress \\
\hline DNA & Deoxyribonucleic Acid \\
\hline ENS & Enteric nervous system \\
\hline EPO & Erythropoietin \\
\hline EPOR & Erythropoietin receptor \\
\hline fMRI & Functional magnetic resonance \\
\hline GABA & Gamma aminobutyric acid \\
\hline GF & Germ-free \\
\hline GSK-3 & Glycogen synthesis kinase 3 \\
\hline HPA & Hypothalamic-pituitary-adrenal \\
\hline IL-6 & Interleukin-6 \\
\hline JB-1 & Lactobacillus rhamnosus \\
\hline KO & Knockout \\
\hline LTD & Long term depression \\
\hline
\end{tabular}




\begin{tabular}{|l|l|}
\hline LTP & Long term potentiation \\
\hline MAPK & Mitogen-activated protein kinase \\
\hline mRNA & Messenger ribonucleic acid \\
\hline NMDA & N-methyl-D-aspartate \\
\hline P75NTR & p75 neurotrophin receptor \\
\hline PFC & Prefrontal cortex \\
\hline PIK-3 & Phosphoinositide 3-kinases \\
\hline PKC & Protein kinase C \\
\hline PLC-y & Phospholipase C-y \\
\hline PTSD & Post-traumatic stress disorder \\
\hline SAM & Sympathetic-adrenal medullary \\
\hline SNP & Single nucleotide polymorphism \\
\hline SNRI & Selective norepinephrine reuptake inhibitors \\
\hline SP & Substance protein \\
\hline SPF & Specific pathogen free \\
\hline SSRI & Selective serotonin reuptake inhibitor \\
\hline tPA & tissue plasminogen activation \\
\hline Trk & Tropomyosin receptor kinases \\
\hline TrkB & Tyrosine kinase B \\
\hline WT & Wild type \\
\hline
\end{tabular}




\section{Truncated Tyrosine Kinase Receptor B (TrkB.T1) plays a role in susceptibility to chronic stress}

\section{Introduction}

\section{Background}

The monoamine treatment approach to depression and anxiety centers around the use of selective serotonin reuptake inhibitors (SSRIs). Various studies and current research indicate that SRRI's may not be as effective in treating depression and anxiety as previously thought. Medical practitioners have utilized various strategies such as switching to another SSRI's if tolerance develops, although the following "switch" does not demonstrate effective results. Therefore, for effective results after tolerance has developed in an individual, the best current practice is to switch to another class of antidepressants that is not an SSRI (Papakostas et al., 2008). Selective norepinephrine reuptake inhibitors (SNRIs) are another class of antidepressants used. Many monoamine treatment approaches seem to be ineffective in some depressed individuals, a term known as SSRI or SNRI refractory. It has been suggested that SSRI/SNRI refractory depressed individuals may be irresponsive due to higher levels of the pro-inflammatory cytokine, interleukin-6 (IL-6) (Yoshimura et a., 2009), which may create an inflammatory milieu that could negatively impact monoamine utilization, as well as adversely affect homeostatic neuroplasticity. In one study looking at a 
single dosage (0.75mg.kg) of setraline (substance of SSRI), it was evident that there is a decrease of IL-6 mRNA expression (Sitges et al., 2014). Interestingly, a drop of IL-6 seem to be an indicator of improvement (Galecki et al., 2018). In order to have an effective treatment of anxiety or depression, multiple factors such as anti-inflammatory processes must be kept in mind. Brain derived neurotrophin factor (BDNF) has been shown through multiple studies to play a major role in the efficacy of anxiety and depression treatment. It has been demonstrated that an individual suffering from depression displays changes in brain derived neurotrophin factor (BDNF) levels as depressed patients (SSRI/SNRI responsive as well as refractory) exhibit decreased levels of BDNF (Yoshimura et a., 2009).

Ketamine is an N-methyl-D-aspartate (NMDA) antagonist that displays rapid response as an antidepressant. Due to NMDA's rapid bioavailability in individuals, antidepressant effects are seen within 1-2 hours after ketamine intake. Though regarding its route of administration, studies have demonstrated that for a more effective response, ketamine should be administered intravenously at a slow pace, likely owing to its unique pharmacokinetic properties (Singh et al., 2016). Normally, NMDA inhibits the BDNF receptor (TrkB, Tropomyosin receptor kinase B), but upon antagonizing the NMDA receptor, the monotonic inhibition on TrkB will be released. This causes the activation of BDNF ligand specific TrkB receptor. By activating TrkB receptor, BDNF levels increase due to increase of protein translation (Yoshii \& Constantine-Paton, 2010). Though ketamine has positive effects on depression, it does not directly affect the hypothalamic-pituitary adrenal (HPA) axis (Brachman et al., 2016). Interestingly, Ketamine also does not have any influence on the neurochemical impact of acute behavioral stressors (Yamada \& Jinno, 
2019). Similar to ketamine, erythropoietin (EPO) seems to also stimulate the BDNF robustly (Osborn et al., 2013).

Ketamine is classified as an ionotropic glutamate NMDA receptor antagonist. Though the mechanism behind ketamine's fast-acting responses towards depressive symptoms is proposed to be by elevating BDNF translation as well as secretion (Garcia et al., 2008). Ketamine not only has effects on BDNF expression, but it also seems to have an effect on inhibiting glycogen synthesis kinase 3 (GSK-3). Furthermore, studies have indicated that by inhibiting GSK-3 in certain regions of the brain such as the hippocampus and the prefrontal cortex (PFC), depressive symptoms are alleviated (Ma et al., 2013). With that being said, the dosage at which ketamine is administered can be very critical in regard to how long ketamine effects last and how rapid its effects commence. It is suggested that ketamine is most effective when administered at low doses $(0.5 \mathrm{mg} / \mathrm{kg})$ through intravenous methods. By giving $0.5 \mathrm{mg} / \mathrm{kg}$ to a patient, the individual can experience relief from depressive symptoms within two hours and such relief can last of to two weeks (Shwartz et al., 2016).

In addition to novel treatment options for depression/anxiety, erythropoietin (EPO) has been introduced as a new target pathway due to its similar effects to ketamine (Osborn et al., 2013). EPO is a hematopoietic growth factor that is mainly involved in effecting the hematopoietic system, but evidence has demonstrated that it has an effect on multiple cells including various immune cells. One main effect of EPO is that upon binding to erythropoietin receptor (EPOR), it demonstrates neurotrophic as well as neuroprotective 
effects (Ma et al., 2016). Interestingly, studies have demonstrated that the induction of EPO through electroconvulsive seizures in an animal model resulted in an increased expression of BDNF particularly in the hippocampus. Furthermore, the following increased expression in BDNF in the hippocampus demonstrated antidepressant like effects (Viviani et al., 2005). Though the following research findings may seem promising, other research studies question the efficacy in treating depressive-like behavior particularly in animal models (Leconte et al., 2011). Regardless of the conflicting results in examining EPO's efficacy in treating depression, one human study indicates that using EPO in treatment resistant depressed patients results in increased plasma levels of BDNF (Vinberg et al., 2015). In addition to mood alleviation, EPO treated patients also displayed an increased bloodoxygen-level-dependent (BOLD) signal via functional magnetic resonance (fMRI) in the left amygdala indicating the amygdala proper activation and response to all kinds of responses including disgust, happy, fearful, and neutral faces (Miskowiak et al., 2008).

\section{Role of neurotrophic factors on anxiety}

BDNF is observed in many regions of the brain such as the prefrontal cortex, hippocampus, thalamus, amygdala, and various other regions. The ligand specific receptors for BDNF are TrkB and p75 neurotrophin receptor (p75NTR), but TrkB has higher affinity to BDNF ( 10-11 M in dissociation constant $(\mathrm{Kd}))$. The p75NTR on the other hand has lower affinity to BDNF ( 10-9 M in Kd) (Razavi et al., 2015; Sakuragi et al., 2013). The precursor peptide is known as pro-BDNF which then transforms into mature BDNF through the trans-golgi apparatus (Greenberg et al., 2009). Through many animal experimental studies, it has been proposed that BDNF may promote antidepressant/anti- 
anxiogenic effects on rodents who undergo learned helplessness and inescapable shock. Levels of BDNF are normally downregulated through undergoing chronic stressors, but the alleviation of depressive-like symptoms are noted when BDNF levels increase in various regions of the brain such as the hippocampus. The mechanistic action of ketamine is that it is a non-competitive NMDA antagonist. Upon the activation of NMDA receptor, ketamine enters the NMDA receptor channel and blocks the flow of cations. Normally, the overactivation of NMDA receptors creates an overflow of calcium $\left(\mathrm{Ca}^{2+}\right)$ influx which causes excitotoxicity within the neuron. Therefore, ketamine works great due to the blockage of overflow of cations such as $\mathrm{Ca}^{2+}$ ions (Liu et al., 2001). Ketamine's high affinity receptor is TrkB, which is located presynaptically and post-synaptically. Therefore, the activation of such receptors stimulates neurotransmitter release as well as postsynaptic responses (Björkholm \& Monteggia, 2016).

\section{Effects of BDNF on anxiety-like disorders}

As mentioned earlier, BDNF has been shown to play a major role in cell survival and neuroplasticity. Abnormal levels of this neurotrophic factor are suggested to induce depressive-like and anxiety-like symptoms (Janke et al., 2015). Further to BDNF's relationship with depressive-like and anxiety-like symptomatology, BDNF is also associated with structural changes in the brain. The following is shown as abnormal decrease in levels of BDNF are demonstrated to have an effect on the hippocampal volume as it decreases the overall volume of the hippocampus (Rizos et al., 2011). Low levels of BDNF as well as impaired secretion of BDNF via Val66Met single nucleotide polymorphism (SNP) are also associated with anxiety-like behaviors as well as mood disorders such as 
depression and obsessive-compulsive disorder (Janke et al., 2015). More interestingly, SNPs in the BDNF gene, Val66Met, has been shown to elevate anxiety-like behaviors in mouse models as well as make them resistant to the efficacy of fluoxetine, a typical SSRI (Bath et al., 2012). Though a large portion of contemporary research on BDNF is focused on specific regions of the brain, such as the hippocampus and prefrontal cortex, BDNF also plays a role in other brain regions. The amygdala is one brain region that completes the limbic system and plays a role in emotional responses. The serotonin system seems to be modulated by BDNF signaling as dysfunction in the BDNF signaling could result in a dysfunction in the amygdala. This mainly has been introduced in the context of posttraumatic stress disorder (PTSD) development (Green et al., 2013). In rodent studies, the amygdala region of the brain is shown to be increasingly affected by chronic stress exposure, particularly in rats, as it has been shown that there is a decrease in volume particularly in the basolateral amygdala (BLA) due to chronic stress exposure (Yang et al., 2006). While on the other hand, chronic stress exposure also resulted in an increase in the dendritic arborization as well as spine density in the BLA (Vyas et al., 2006).

As noted by multiple research studies, the HPA axis plays a large role in stress responses. Stress corticotrophin releasing hormone (CRH) from the hypothalamus can affect BDNF. In a rat study investigating the effects of chronic stress (3h restraint/day) on HPA and BDNF, it is demonstrated that rats who underwent chronic stress exhibited dysregulation in HPA axis as the baseline mRNA and peptide content of CRH and argininevasopressin (AVP) were significantly increased. The plasma concentrations of adrenocorticotropic hormone (ACTH) and corticosterone (CORT) were also increased. 
Interestingly, BDNF basal content was also modified as it was increased in multiple brain regions including the hippocampus, hypothalamus and pituitary in chronically stressed mice. On this note, pathological fear states are suggested to result from a chronic increase in glucocorticoids which seem to influence the regulation of BDNF expression (Gourley et al., 2009).

In addition to the relation between BDNF and HPA axis, the amygdala is prominently responsible for consolidating fear memory. After pairing a conditioned stimulus (sound of a tone) with unconditioned stimulus (electric foot shot), an increase in BDNF mRNA as well as TrkB phosphorylation was exhibited in the basolateral amygdala (Rattiner et al., 2004). Also, it seems that there is a positive correlation between amygdala BDNF levels and anxiety-like behavior in the elevated plus maze (Yee et al., 2006). Upon fear conditioning, activation of TrkB by BDNF in prevalent in the amygdala and this activation results in activating mitogen-activated protein kinase (MAPK) as well as phosphoinositide 3-kinases (PI3K) (LC \& PW, 2006). The activation of MAPK cascade signaling results in the consolidation of fear memory as well as synaptic plasticity (Schafe et al., 2000).

It is suggested that BDNF interacts with multiple processes effects the amygdala in fear memory consolidation. One factor that BDNF seems to highly and strongly effect is the gamma aminobutyric acid (GABAergic) neurons present in the amygdala. One example, GABAergic receptors are rapidly decreased in fear conditioning. This prominent decrease is shown to be in the amygdala (Heldt \& Ressler, 2007). This decrease of GABAergic receptors 
indicates a hyperexcitability of the membrane. Also, this internalization of GABA(A) receptors seem to be BDNF-TrkB dependent as the activation of BDNF-TrkB in memory consolidation is activated/proceeded by the activation of protein kinase C (PKC) (Mou et al., 2011). In addition to memory consolidation, PKC also plays a major role in cyclic adenosine monophosphate (CAMP) response element-binding protein (CREB) transcription as well as neuroplasticity due to the fact that activation of BDNF-TrkB leads to the activation of phospholipase C-y (PLC-y) pathway (Bjorkhlom \& Monteggia, 2016). Activation of the PLC-y pathway through BDNF-TrkB leads to increased plasticity in its respective region, hence stronger activation of within the region.

\section{Effects of BDNF on long-term potentiation and synaptic plasticity}

NMDA is one type of ionotropic glutamate receptor that is located on the presynaptic terminal. It plays a major role in the regulation of $\mathrm{Ca}^{2+}$ influx. The NMDA receptor is at least partly modulated by levels of BDNF, since as elevated levels of the trophic factor was associated with increased NMDA and intracellular $\mathrm{Ca}^{2+}$ levels (Bjorkholm \& Monteggia, 2016). Further, long-term potentiation (LTP) and synaptic plasticity on the presynaptic terminal can be strengthened by the modulation of BDNF levels. The above phenomenon was introduced and described by a study conducted on BDNF knockout neurons in mouse neocortical glial cells. In this study, the researchers investigated the effects of BDNF on presynaptic long-term plasticity in regard to NMDA receptor activation. They observed the strength of active cycling presynaptic vesicles through styryl dye FM4-6. BDNF knockout neocortical neurons seemed to have significant decrease in the fluorescence intensity (Walz et al., 2006). 
Implications in the dendritic spine density particularly in the hippocampus seems to play a crucial role in depression and anxiety related disorders. Upon exposure to chronic stress, there seems to be dendritic retraction particularly in the CA3 region of the hippocampus (Adamec et al., 2011). In addition, a reduction in the overall CA3 hippocampal volume seems to be significant when exposed to chronic stress (Donohue et al., 2006). Long term depression (LTD) and LTP have been a topic of interest in regard to BDNF. The difference on how LTP and LTD would rise is due to the different cleaving of BDNF. Prior to BDNF synthesis, BDNF has a precursor called proBDNF. ProBDNF is cleaved proteolytically through the activation of tissue plasminogen activation (tPA), which eventually produces mature BDNF (Musumeci \& Minichiello, 2019). LTP is initiated upon cleaving of proBDNF by tPA process to generate mature BDNF (Pang et al., 2004). On the other hand, LTD is facilitated by the proBDNF-p75neurotrophin receptor signalling (Woo et al.,2005). LTD is accomplished due to the activation of p75 NTR receptors via proBDNF. That being said, it should be noted that proBDNF is suggested to promote apoptosis (leading to LTD) while BDNF promotes cell survival via TrkB receptors (leading to LTP) (Bjorkholm \& Monteggia, 2016). With all this information on p75NTR, it should not be insinuated that it only promotes cell death as many other research studies indicated that p75NTR has multiple functions on neurons as well as glial cell. For example, in Schwann cells, BDNF binding to this receptor promoted remyelination post-injury. Depending on the cell cortex, p75NTR can either facilitate or attenuate proliferation (Meeker \& Williams, 2015). With all that being said, it can be insinuated that BDNF can facilitate both LTP and LTD depending on the mechanistic of action it pursues. LTP is achieved by either enhancing 
neurotransmitter release presynaptically, or by sustained blockage of NMDA receptors at rest (Erinn et al., 2014).

\section{TrkB (FL and T1) and Anxiety}

There are three predominant tyrosine kinase receptors (Trk), TrkA, TrkB, and TrkC. The TrkB receptor is a specific ligand receptor particularly related to BDNF (Dienhardt \& Chao, 2014). For a vast majority of time it has been thought that TrkB is present only in one form, but it is now acknowledged that there are a few variations in isoforms that are created through the cleaving of the main TrkB receptor, TrkB.FL, TrkB.T1 and TrkB.Shc receptor isoform. The primary role of TrkB.T1 receptor is to act as a dominate negative regulator (or inhibitor) of the function of TrkB.FL (full length). It helps regulate BDNF signaling through the regulation of the extracellular TrkB.FL. It should also be noted that TrkB.T1 lacks the intracellular domain found on the full-length form (Carim-Todd et al., 2009).

Previous studies looking at TrkB.T1 and anxiety related disorders are relatively scarce, as only one study on record exists in regard to selectively deleting the TrkB.T1 receptor to examine its effects on the brain. Carim-Todd et al. (2009) is one of the few researchers who examined the pathological aspects of knocking out the TrkB.T1 receptor. In their study, Carim-Todd et al. discovered deleting the TrkB.T1 but retaining the TrkB.FL receptor resulted in pathological abnormality of neurites of neurons regarding the length 
and complexity in the BLA. The following goes hand in hand with the behavioral observations noted as TrkB.T1 knockout (KO) mice exhibited an increased anxiety phenotypic behavior in the open field test and elevated plus maze, compared to wild type. It is important to note that no morphological changes were present in the hippocampal region, nor were any behavioral changes present (although deficits in LTP were observed).

Remarkably, TrkB.T1 is the only isoform that is expressed on astrocytes. Yet, there is a paucity of studies that have investigated the effects of TrkB.T1 on these glial cells. Although the in-depth function of TrkB.T1 on astrocytes is not yet well understood, it was suggested that TrkB.T1 activation stimulates intracellular $\mathrm{Ca}^{2+}$ signaling in glia cells (Rose et al.,2003). A recent study investigating the role of TrkB.T1 on astrocytes revealed that the global deletion of TrkB.T1 in mice model subjects resulted in a decreased volume of astrocytes. Interestingly, it was also evident that the peri-synaptic genes which are important in astrocyte functioning were dysregulated (Holt et al., 2019).

\section{Gut microbiota on BDNF-TrkB and Anxiety}

In recent years, research has demonstrated an increased relationship between the gut microbiota and neurological disorders. Specifically, disorders such as anxiety and depression have been a focus of study, as studies conducted by Nardone \& Compare, 2014; Vuong et al., 2017; Rogers et al., 2016 explain the complex relationship between gut microbiota with anxiety and depressive related symptomatology. With the above researchers in mind, it is demonstrated that dysregulation of gut microbiota can lead to anxiety-like and depressive-like symptomatology in rodents. For example, an intrinsic look 
at how gut bacteria can affect mouse behavior was analyzed by Sudo et al. (2004) where it is demonstrated that germ free (GF) mice exhibit increased response of ACTH and levels of CORT when they underwent chronic stress, compared to house specific pathogen free (SPF) mice. Although these results may not disclose the exact mechanisms involved in how gut microbiota affect behaviour, they are indicative that the gut bacteria have a relationship with certain neurological disorders such as anxiety and depression.

When examining communicative pathways between the gut and the brain, one should pay close attention to the vagus nerve. The vagus nerve is thought to be the main communicative pathway between the gut and the brain, and this pathway is also suggested to be bidirectional (Forsythe et al., 2014). Recently, researchers have examined how disruption of the vagus nerve affects neurotransmitter presence in specific regions of the brain. The following has been conducted in an effort to demonstrate how gut bacteria can affect neurological processes. For example, a study conducted by O'Leary et al. (2017) suggests disruption of the vagus nerve can results in a decrease in BDNF mRNA expression within the CA1, CA3 and dentate gyrus of the hippocampus. Furthermore, measurements of bromodeoxyuridine / 5-bromo-2'-deoxyuridine (BrdU)-positive cells per section indicate vagotomised mice express a decreased survival rate of newly born cells in the dorsal and ventral hippocampus (O’Leary et al., 2017). The following is extremely important when understanding how gut microbiota can affect neurological processes as O’Leary et al. indicate disruption of communicative pathways between the gut and the brain result in significant differences in BDNF mRNA and cell survival rate within the hippocampus. With 
the following provided, one can begin to understand the implicit effects the gut can have on neurological function.

Understanding the effects of gut microbiota on the brain is increasingly important when understanding how the gut can affect neurological changes within specific regions of the brain. Heijtz et al. (2011) examine the following while comparing BDNF mRNA expression between GF and SPF mice. Within the following study, it is demonstrated that GF mice exhibit decreased BDNF mRNA expression within the amygdala, hippocampus and cingulate cortex when compared to SFP mice. Furthermore, neurological difference between GF and SFP mice are supported by behavioural related symptoms. For example, Heijtz et al., 2011 performed a light/dark preference test on both GF and SFP groups, where they examined group preferences on light or dark settings given that the GF mice had been exposed to gut microbiota early in life. Compared to control SPF mice, GF mice spent significantly more time in the light compartments than dark, indicating an increased anxiolytic state. Additionally, BNDF mRNA expression is shown to be decreased in various regions of the brain in GF mice compared to SPF mice. The following includes having decreased BDNF mRNA expression in orbital frontal cortex, anterior olfactory region, CA1, BLA, and cingulate cortex. The following would suggest that colonization of gut flora could influence the underlying neural circuitry for anxiety and fear.

As we continue to examine how the gut microbiota effects neurological processes within the brain, it becomes increasingly clear that BDNF plays a crucial role in this relationship. Not only does gut microbiota effects BDNF mRNA in regions of the brain such 
as amygdala, hippocampus and cingulate cortex, but BDNF also seems to have an important role to play in enteric nervous system (ENS) function and balance. Various studies look into the presence of BDNF in the ENS specifically in colonic epithelial cells as well as enteric glia cells (Wang et al., 2015 \& Steinkamp et al., 2012). The expression of BDNF and TrkB immunoreactivity in the gut has been shown in guinea pig ileum and is expressed in various regions. These regions include the expression of both BDNF and TrkB in the submucosal plexus, myenteric plexus, myenteric ganglia, and interganglionic connectives. Furthermore, BDNF immunoreactivity is shown in mucosal epithelial cells, mucosal villi, and subsets of myenteric neurons. TrkB immunoreactivity is shown prominently in the mucosa. BDNF and TrkB is also evident in cultures of myenteric neurons (Boesmans et al., 2008).

When looking at the mechanistic of action of BDNF and TrkB in the gut, it seems that BDNF does not have a direct effect on $\mathrm{Ca}^{2+}$ signalling as it does in the hippocampus (Kafitz et al., 1999). Although BDNF does exhibit indirect effects on $\mathrm{CA}^{2+}$ signalling within the enteric nervous system (ENS). The following is shown as BDNF in cultured myenteric neurons influences $\mathrm{Ca}^{2+}$ signalling in a time-dependent manner through serotonin (5-HT) and substance protein (SP). This is facilitated as 5-HT and SP gradually increased after several hours of exposure to BDNF which then results in increased $\mathrm{CA}^{2+}$ signalling. The relationship between BDNF and indirect mechanisms leading to $\mathrm{CA}^{2+}$ signalling was examined further by Boesmans et al. (2008) where TrkB receptors in the gut were blocked. As a result of blocking TrkB receptors, $\mathrm{CA}^{2+}$ signalling ceased entirely which demonstrates BDNF's indirect effects on $\mathrm{CA}^{2+}$ signalling within the ENS. 
Evidence has emerged regarding synaptic transmission in the ENS as peristaltic reflex in the rat colon is shown to be augmented by BDNF. In this process, BDNF stimulates the release of 5-HT and calcitonin gene related peptide that facilitates mucosal activity (Grider et al., 2003). Therefore, it is demonstrated that BDNF plays a significant role in the normal function of gut peristaltic reflex.

Anxiety and gut bacteria are largely influenced by each other as various studies indicate a disbalance in the gut bacteria can lead to anxiety like symptoms, and the anxiety like symptoms can lead to a disbalance in the gut bacteria (Savignac et al., 2014; Park et al., 2013, Kelly et al., 2013). Four major gut phyla include Firmicutes, Bifidobacteria, Actinobacteria, and Proteobacteria (Khanna \& Tosh, 2014). Among the following major gut phyla, an imbalance can result in anxiety like symptoms (See review: Clapp et al., 2017). For example, in a study conducted investigating the role of 2 bifidobacteria strain (B.longum 1714 and B.breve 1205) and escitalopram (an SSRI) in innately anxious mice (BALB/c mice), both bifidobacteria strains showed lower anxiety-like symptoms in marble burying test. Interestingly, escitalopram has also showed reduced anxiety levels in the marble burying test. B. longum 1714 showed reduced stress induced hyperthermia and reduced anxiety like behavior in tail suspension test. B. breve 1205 showed lower anxiety levels in the elevated plus maze (Savignac et al., 2014). In addition to the following, Lactobacillus strain in the intestine play a role in depressive and anxiety disorders as it is shown to influence brain regions associated with depressive and anxiety disorders. Such brain regions include the amygdala, hippocampus and prefrontal cortex. Lactobacillus 
bacterial strain was suggested as a probiotic to help the relieve of anxiety and depressive like symptoms. Chronic treatment of Lactobacillus rhamnosus (JB-1) in BALB/c mice showed a reduction of GABA-B1b mRNA expression in amygdala, hippocampus and locus coeruleus. Alternatively, GABA.A $\alpha 2$ mRNA expression is shown to be increased in the amygdala and prefrontal cortex but decreased in the hippocampus. Regarding anxietybehavioral measures, JB-1 treated mice showed an anxiolytic effect in the open field test as these mice showed increased number of entries compared to controls (broth fed mice). Additionally, JB-1 treated mice showed significant less time being immobile in forced swim test (depressive-behavioral measure) compared to controls. Corticosterone (CORT) levels are shown to be lower in JB-1 treated mice compared to controls (Bravo et al., 2011). CORT is considered to be a stress hormone in rodents and is normally produced following stimulation of the HPA axis. Therefore, the measure of CORT is normally evaluated as a measure of stress in rodents (Prickaerts \& Steckler, 2005). This decreased CORT in the JB-1 treated mice suggests that the probiotic lactobacillus displayed anxiolytic effects in innately anxious mice. In order to test whether or not probiotic lactobacillus effects the brain directly, vagotomised mice were used for this investigation. Vagotomised mice prevented JB-1 treated mice to exhibit anxiolytic effects in the open field test as they have shown to spend less time in the center zone compared to sham surgery mice. In regard to GABA mRNA expression in the brain, vagotomised mice displayed decreased levels of GABA.A $\alpha 2$ in BLA and central nucleus of the amygdala (CeA) of the amygdala compared to sham surgery mice. (Bravo et al., 2011). 


\section{Thesis Aim}

This study aims to investigate the effects of the TrkB.T1 receptor on anxiety-like pathology. In the past, researchers have paid prominent attention to BDNF and its specific ligand receptor TrkB.FL on its role in anxiety-like disorders, but little to no attention has been placed on the effects of the receptor's isoform, TrkB.T1.

Therefore, the functional aspect of TrkB.T1 will be examined using behavioral measures as well as anatomical measures. In addition, the gut microbiota will be analyzed due to its remarkable connectivity with depression and anxiety. When relating gut bacteria to functional aspects within the brain, it has been demonstrated that BDNF and gut microbiota seem to be strongly connected. In fact, as demonstrated previously, gut microbiota seems to influence the expression of BDNF mRNA in certain brain regions.

The following research study will assess the impact of chronic unpredictable stress (CUS) (35 days of CUS) in adult mice (8-10 weeks of age). Chronic unpredictable stress is a paradigm that is used for rodents. It is composed of exposing the rodent to repeated exposure of stressors that are unpredictable. These stressors last for weeks depending on the stressors used for the rodents (Sequeira-Cordero et al., 2019). Our adult mice will vary in genotype (TrkB.T1 knockout versus wild type), sex (male versus female), and treatment (stress versus control). We assessed this CUS impact using the behavioral test known as the "open field test". The open field test measures anxiety-like symptoms by looking at the movement of the mice in an open field apparatus. We hypothesize to observe control mice being less anxious-like compared to stress. We also hypothesize the genotypic difference in 
relation to anxiety-like behavior as by theory, TrkB.T1 knockout (KO) mice should show heightened anxiogenic behavior compared to wild-type mice (WT). Additionally, this thesis also involves the investigation of the expression of TrkB.FL in the amygdala region as the amygdala is mainly involved in anxiety and fear responses. With respect to the gut flora, we aim to explore the gut flora changes/differences in treatment groups, sex differences, and genotypic differences. We hypothesize that the control group will not have any significant changes in microbiota, while the stress group will exhibit significant changed/deviated scale of the microbiota.

\section{Aim 1}

To determine if 35 days of chronic unpredictable stress with 2X daily manipulations will provide anxiogenic-like behavior mice of different treatment (control vs stress), sex (male vs female), and genotype (wild type vs TrkB.T1 knockout). Open field test is the behavioral measure we will pursue in order to examine the anxiogenic-like symptoms of the mice.

\section{Aim 2}

To investigate the TrkB.FL receptor expression in the amygdala after the mice have been exposed to the CUS paradigm. It should also be noted that we will also investigate the TrkB.FL protein expression in all mouse groups.

\section{$\operatorname{Aim} 3$}

We aim to determine if any changes are present in the gut flora due to chronic stress exposure between different groups (treatment $\mathrm{x}$ genotype $\mathrm{x}$ sex). 


\section{Hypothesis}

We hypothesize that an increased anxiogenic phenotype would be evident in the stress group compared to controls. Additionally, we hypothesize within-group differences as stress KO mice will display increased anxiogenic phenotype compared to stress WT mice. Regarding TrkB.FL expression in the amygdala, we hypothesize stress KO mice will display an increased expression, compared to stress WT mice, of the TrkB.FL receptor due to the functional aspect of TrkB.T1 receptor on full length (as TrkB.T1 is shown to have dominant negative inhibition on TrkB.FL). Lastly, in regards to analyzing the effects of stress on gut flora, we hypothesize that chronic stress will result in a decrease of bifidobacteria (B.longum 1714 strain and B.breve 1205 strain) in stressed WT mice compared to control WT mice. Additionally, Lactobacillus rhamnosus is hypothesized to be reduced in stress WT mice compared to control WT mice. Regarding genotypic differences and gut flora, we expect to see a significant decrease of bifidobacteria (B.longum 1714 strain and B.breve 1205 strain) and Lactobacillus rhamnosus in stress KO mice compared to stress WT. We expect alterations in these species due to the fact that they have been shown to be decreased in the gut after mice have exhibited depressive as well as anxiety related symptoms

\section{Methods}

Animals and experimental design 
Subjects in the following research study are laboratory mice strain C57BL/6J. They will be either TrkB.T1 knockout or wildtype mice, and both genders will undergo the experiment. Three cohorts will be used having a total number of 140 mice (Cohort $1=24$, Cohort $2=55$, \& Cohort $3=61$ ). Prior to behavioral measures, mice will be cohoused until 810 weeks of age and will be randomly separated into stress and control treatment groups after this period. They will be singly housed in standard cages upon entering the experiment. Prior to the initiation of CUS, all mice will undergo 5 days of behavioral baseline tests, a sucrose preference test, refer to Table 1. In addition, fecal boli samples will be collected from both groups. Following the behavioral baseline test, mice will undergo the CUS for 35 days including $2 \mathrm{x}$ daily manipulations, refer to Table 2 on page 28 . Following 35 CUS, all mice will be tested using the behavioral baseline test, and sucrose preference test. Behavioral tests such as the open field test as well as the alternate Y-maze will be used following the last sucrose preference test. In addition, fecal boli samples will be collected post chronic stress. In order to investigate the neuroanatomical changes, half of the mice per group will be euthanized via rapid decapitation for Western blot measures. The second half of the mice per group will be euthanized via $100 \mathrm{mg} / \mathrm{kg}$ sodium pentobarbital and perfused with paraformaldehyde for immunohistochemistry measures. Western blotting will be used to look at TrkB FL receptor (by looking at pTrkB-Y816 and unphosphorylated TrkB.FL) in the amygdala. As mentioned earlier, in order to investigate the microbiota of the following mice, fecal boli will be collected pre \& post-chronic unpredictable stress. 
Table 1: Timeline table.

\begin{tabular}{|l|r|r|r|r|r|r|r|r|r|r|r|r|r|r|}
\hline Days & 1 & 2 & 3 & 4 & 35 Days & 36 & 37 & 38 & 39 & 40 & 41 & 42 \\
\hline & Suc Pref & Suc Pref & Suc Pref & Suc Pref & CUS & CTL Suc Pref & STR Suc Pref & BBK & OF - CTL & OF - STR & Alt Y m - CTL & Alt Y m - STR \\
\hline
\end{tabular}

Table 2: Chronic unpredictable stress schedule:

\begin{tabular}{|l|}
\hline Restraint 15 minutes \\
\hline Restraint 20 minutes \\
\hline Restraint 30 minutes \\
\hline Cinnamon scent \\
\hline Peppermint scent \\
\hline wintergreen scent \\
\hline Eucalyptus scent \\
\hline Lights on - all day \\
\hline Lights off - all day \\
\hline Lights on 12 hours \\
\hline Lights off 12 hours \\
\hline Cage tilt \\
\hline Wet bedding \\
\hline Soaked bedding \\
\hline Empty cage \\
\hline
\end{tabular}

Behavioral measure: Open field test

Following CUS sucrose preference test, all mice were examined for anxiogenic-like symptoms. This involved the behavioral measure open field test. The first day after sucrose preference test, control mice were measured anxiety-like symptoms. On the second day of post sucrose preference test, stress mice were then examined in the open field test. 


\section{Sacrifice}

Half of each treatment group is euthanized via rapid decapitation. The rapid decapitation euthanasia process is for protein analysis, TrkB.FL expression in the amygdala. In short, the mice were rapidly decapitated through the cervical vertebrae via surgical scissors. Multiple regions of the brain were extracted including the prefrontal cortex, hippocampus, amygdala, and the nucleus accumbens. These brain regions were collected using a chilled micro-dissecting block with $0.5 \mathrm{~mm}$ slots. Then using a micropunch, the brain specific regions were collected. The tissues were then placed in vials on ice for Western blot usage. The other half of each treatment group were euthanized via $100 \mathrm{mg} / \mathrm{kg}$ sodium pentobarbital and perfused with $4 \%$ paraformaldehyde for brain tissue analysis via immunohistochemistry. The brain was extracted and rapidly after flushing the blood out using $5 \mathrm{ml}$ saline, the brain tissue was placed in a 4\% paraformaldehyde vial and placed on ice. The brain tissue was then freeze at $-20 \mathrm{C}^{\circ}$.

\section{Western blot}

The expression of TrkB.FL was examined in the amygdala using Western blot. The gels were created with $7.5 \%$ separating gel comprised which comprised of $3.75 \mathrm{ml}$ of Acrylamide and $100 \mu \mathrm{L}$ of $10 \%$ APS and stacking gel. Prior to loading the proteins in the gel electrophoresis, sodium dodecyl sulfate was added to the protein to allow the protein to unfold creating a linear shape as well as coat the chain with a negative charge to allow the natural migration of the proteins from a negative charge to a positive charge. The gels were then placed on the running gel. The gels then were transferred onto blocking membranes. Following transfer, the membranes were left overnight to dry. On the next day, blocking, 
primary (1:1000 pTrkB ABN1381 Rabbit \& 1:1000 TrkB BD610101), and secondary (1:15000 680nm LiCor Rabbit for pTrkB \& 1:1500 800nm LiCor for TrkB Mouse) antibody were used to determine phosphorylated TrkB.FL (pTrkB.FL) (ABN 1381). After imaging the pTrkB.FL, the membranes were stripped then blocked for 30 minutes. After 30 minutes of block, the primary antibody for the unphosphorylated TrkB.FL (BD 10102) was placed for overnight. On the $3^{\text {rd }}$ day, the secondary antibody for the unphosphorylated TrkB.FL was placed following imaging of the membranes at 700nm channel and $800 \mathrm{~nm}$ channel using LICOR.

\section{Gut Microbiota}

Fecal boli samples were taken prior to the start of the CUS, then recollected after the 35 days of CUS. Regarding the fecal boli samples being collected prior to CUS, both treatment groups (stress and control) mice were placed in empty cages for 10 minutes to collect the fecal boli samples. Fecal samples were placed in vile tubes and placed on dry ice. Both treatment group fecal samples were collected in order to maintain the consistency of undergoing techniques. Following the 35 days of CUS, mice fecal boli samples were collected from the open field apparatus box after the mice have been retuned into their standard housing cage. DNA extraction was performed on all fecal boli samples using Norgen stool kit (Cat No 27600). The DNA concentration was then measured and documented. The only fecal extracted DNA samples were used are the ones greater than 10ng/ul for sufficient analysis of the gut flora. The DNA samples were then sent to the integrated microbiome resource in Dalhousie University for analyzing the profile of all the gut microbiota. 


\section{Statistical analysis}

The data collected for TrkB.FL protein expression as well as open field test were analyzed using 2x2x2 ANOVA (treatment, sex, genotype) through SPSS (version \#25). Significant differences were considered at p-value $<0.05$. GraphPad Prism 5 was used to generate a 3-way interaction graph.

\section{Results}

\section{Open Field Test}

Using a Multivariate ANOVA to analyze the open field test, it was shown that there was a significant treatment effect regarding the Small Center Frequency as the Stress group had higher Small Center Frequency compared to Control group, $\left(F_{(1,126)}=36.417, p<0.001\right)$, refer to Figure 1. Additionally, the Stress group took significantly shorter time to enter the Small Center compared to the Control group, $\left(\mathrm{F}_{(1,126)}=7.316, \mathrm{p}=0.008\right)$ (Figure 2). This was not only evident in the Small Center region, but also in the Large Center region of the open field test as the Stress group had significantly higher Large Center Frequency and lower latency to enter Large Center, $\left(\mathrm{F}_{(1,83.43)}=55.826, \mathrm{p}<0.001\right)$ and $\left(\mathrm{F}_{(1,1.94)}=4.064, \mathrm{p}=0.046\right)$ respectively. Figures 3 and 4 illustrates the differences. A 3-way interaction between Sex, Genotype and Treatment was shown to be significant in regards to Large Center Cumulative Duration $\mathrm{F}_{(1,126)}=3.960$, $\left.\mathrm{p}=0.049\right)$. Using Bonferroni-adjusted pairwise comparisons as follow-up analysis, we found that male Control KO mice spent less time in 
the Large Center compared to female Control KO mice $F_{(1,126)}=4.882, p=0.029$, refer to Figure 5.

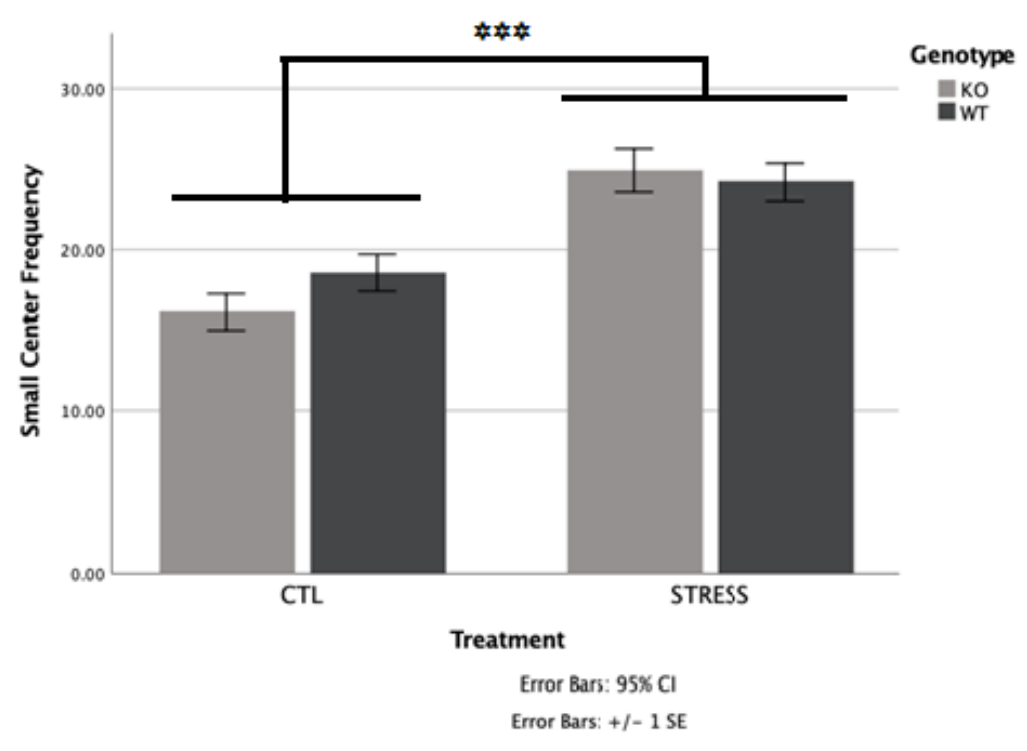

Figure 1. OFT: Small Center Frequency.

Stress group had significantly higher small center frequency compared to Control group $\left(\mathrm{F}_{(1,126)}=36.417, \mathrm{p}<0.001\right)$.

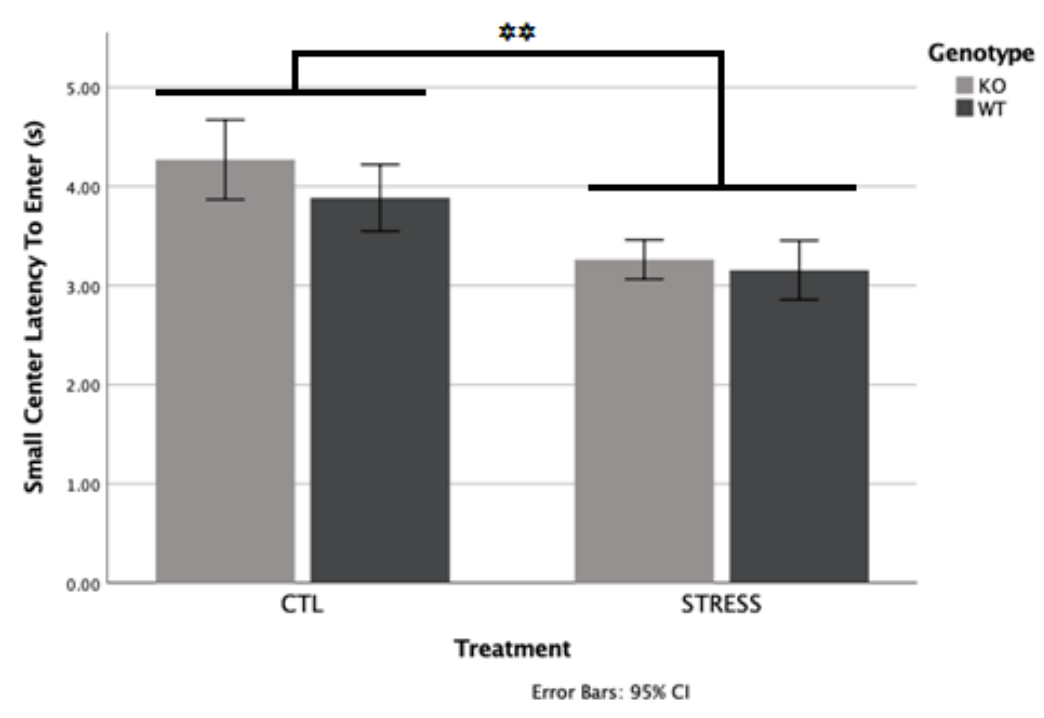

Figure 2. OFT: Small Center Latency to Enter. 
The stress group took significantly shorter time to first enter the small center zone compared to Control group $\left(\mathrm{F}_{(1,126)}=7.316, \mathrm{p}=0.008\right)$.

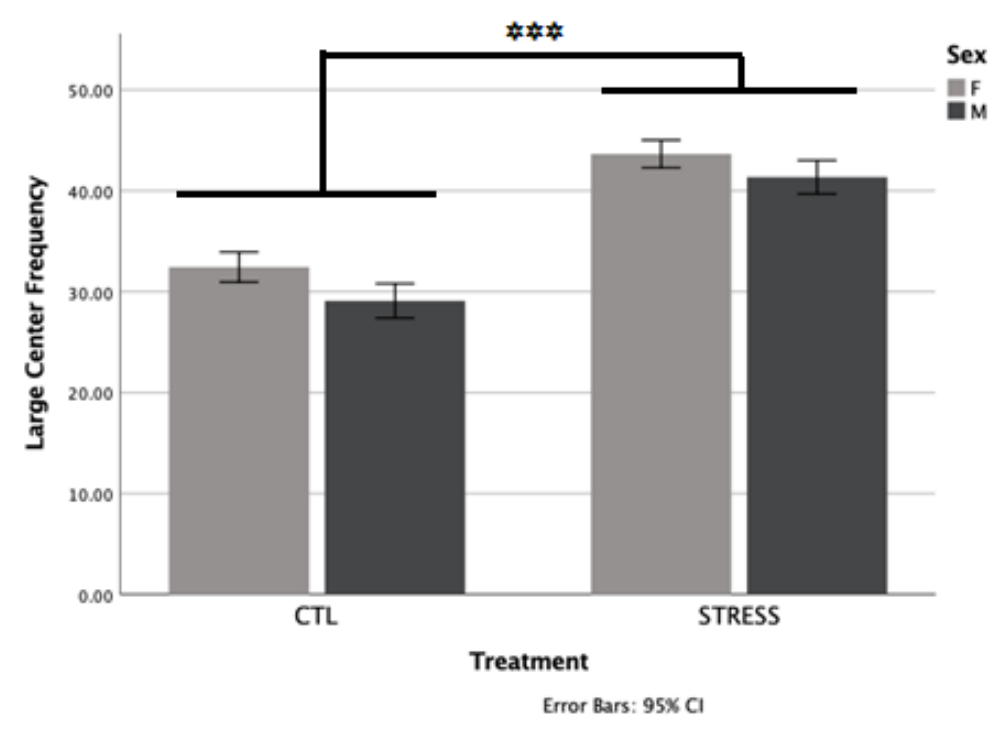

Figure 3. OFT: Large Center Frequency.

Stress group high significantly higher frequency in the large center compared to Control group $\left(\mathrm{F}_{(1,83.43)}=55.826, \mathrm{p}<0.001\right)$.

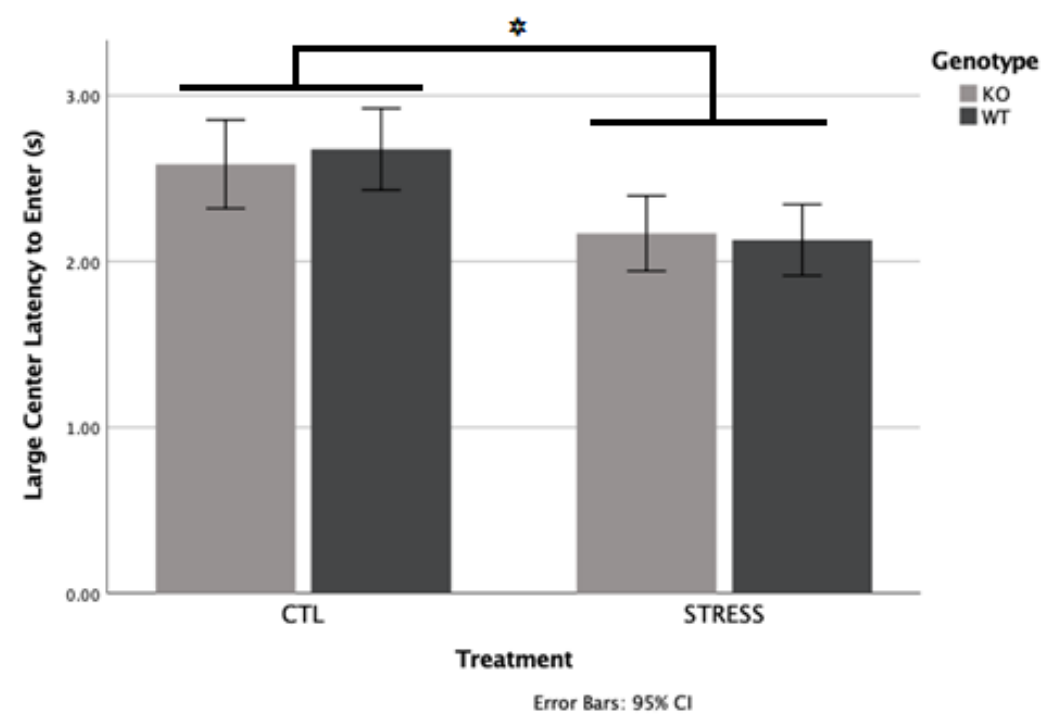

Figure 4. OFT: Large Center Latency to Enter. 
Stress group took significantly shorter time to first enter the large zone $\left(\mathrm{F}_{(1,1.94)}=4.064\right.$, $\mathrm{p}=0.046)$.

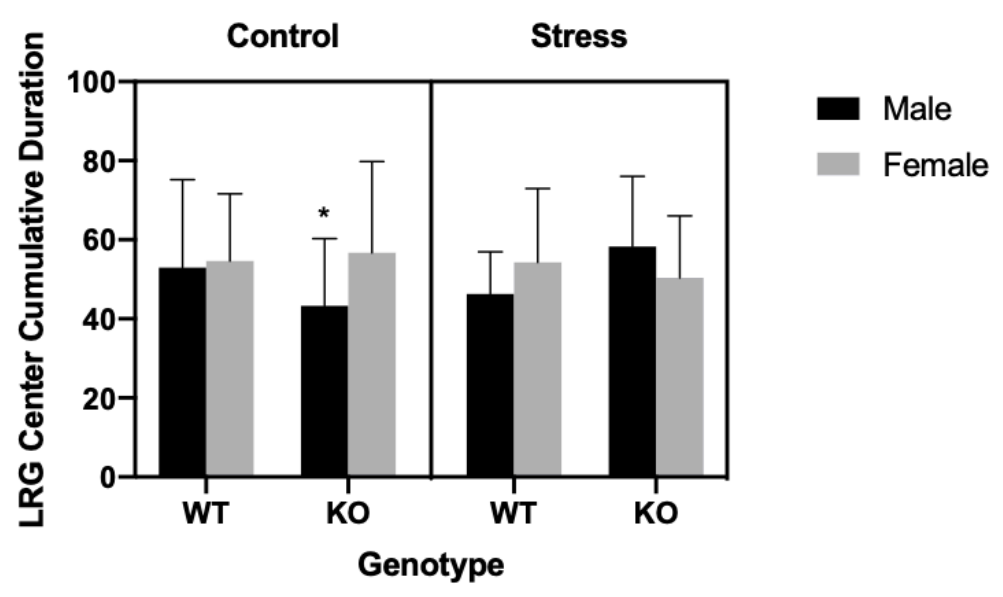

\section{Figure 5. OFT: Large Center Cumulative Duration.}

Only Control male KO mice had significantly lower cumulative duration in the large center zone compared to Control female $\mathrm{KO} \mathrm{F}_{(1,126)}=4.882$, $\mathrm{p}=0.029$.

Additionally, there is also a Treatment effect in regard to the Corner Frequency $F_{(1,126)}=60.995, p<0.001$ as the Stress group had higher frequency compared to Control group (Figure 6). There was also a 3 way interaction between Treatment, Sex, Genotype and Corner Frequency $\mathrm{F}_{(1,126)}=3.283, \mathrm{p}=0.072$. Bonferroni-adjusted pairwise comparison as follow-up analysis indicated that Stress female KO and WT mice had higher corner frequency compared to their Control counterparts, $F_{(1,126)}=15.721, p<0.001$ and $F_{(1,126)}=53.60, p=0.022$ respectively. Stress male KO and WT also had higher Corner frequency compared to their Control counterparts, $F_{(1,126)}=14.621, p<0.001$ and $F_{(1,126)}=29.929, p<0.000$ respectively (Figure 6). 


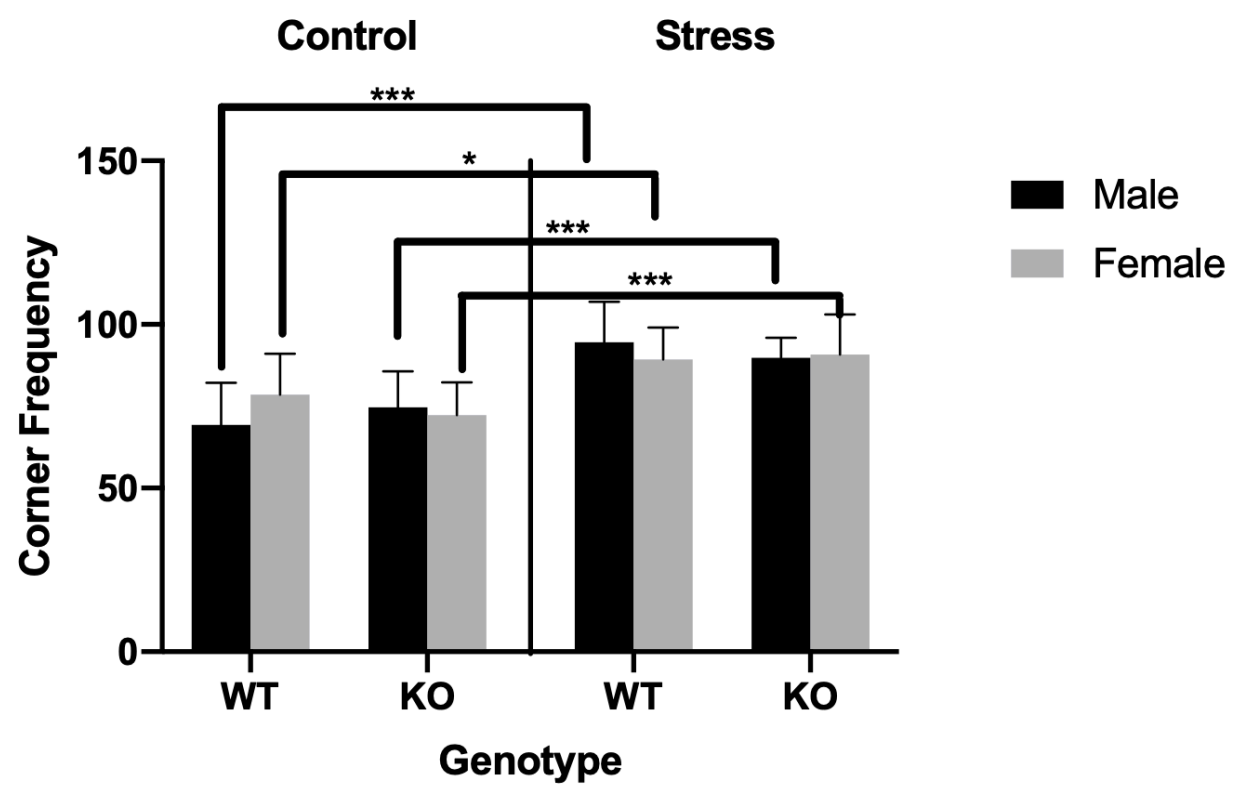

Figure 6. OFT: Corner Frequency.

Both Stress female KO mice and Stress female WT mice are shown to have had significantly higher Corner Frequency compared to their Control counterparts $F_{(1,126)}=15.721, p<0.001$ and $F_{(1,126)}=5.360, p=0.022$, respectively. Both Stress male KO and Stress male WT mice are also shown to have had higher Corner Frequency compared to their Control counterparts $\mathrm{F}_{(1,126)}=14.621, \mathrm{p}<0.001$ and $\mathrm{F}_{(1,126)}=29.929$, $\mathrm{p}<0.001$, respectively.

Through a multivariate ANOVA, there was a Treatment effect on the Total Distance travelled as the Stress mice traveled greater distance compared to Control mice $\mathrm{F}_{(1,126)}=78.025, \mathrm{p}<0.001$, refer to Figure 7. Additionally, there was a borderline significant 3-way interaction (Treatment, Genotype, Sex) on the Total Distance travelled $F_{(1,126)}=3.829$, $\mathrm{p}=0.053$. To tease this difference apart further using Bonferroni-adjusted pairwise comparison, revealed that female Stress KO mice had greater Total Distance compared to female Control KO mice $F_{(1,126)}=20.416, p<0.001$. This was also evident in female Stress WT mice as they have shown to have traveled greater distances compared to female Control WT mice $F_{(1,126)}=7.312, p=0.008$. Male Stress KO mice as well as male Stress WT mice had also shown to have greater Total Distance compared to their Control counterparts, 
$\mathrm{F}_{(1,126)}=18.783, \mathrm{p}<0.001$ and $\mathrm{F}_{(1,126)}=36.726, \mathrm{p}<0.001$ respectively. Please refer to Figure 7 for a visual representation of the Bonferroni-adjusted pairwise comparison follow-up analysis. Additionally, through Bonferroni-adjusted pairwise comparison, female Control WT mice is shown to have greater Total Distance compared to male Control WT mice $\mathrm{F}_{(1,126)}=8.480, \mathrm{p}=0.004$, refer to figure 8 .

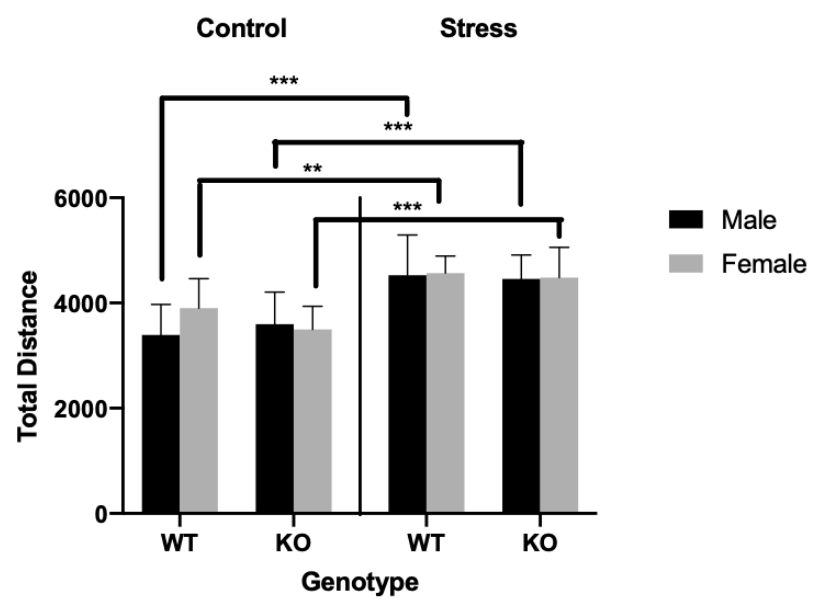

Figure 7. OFT: Total Distance (cm).

Both Stress female KO mice and Stress female WT mice had significantly greater total distance compared to their Control counterparts $F_{(1,126)}=20.416, p<0.001$ and $F_{(1,126)}=7.312$, $\mathrm{p}=0.008$ respectively. Stress male KO mice and Stress male WT mice also had significantly greater total distance compared to their Control counterparts $F_{(1,126)}=18.783, p<0.001$ and $\mathrm{F}_{(1,126)}=36.726, \mathrm{p}<0.001$ respectively. 


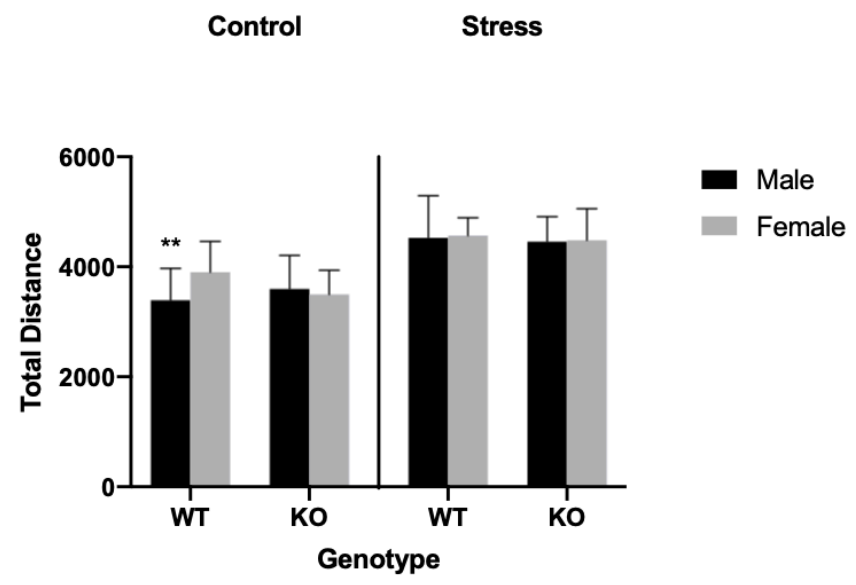

Figure 8. OFT: Total Distance (cm).

There is a sex difference, such that Control female WT mice had significantly greater Total Distance compared to Control male WT mice $\mathrm{F}_{(1,126)}=8.480, \mathrm{p}<0.004$.

Additionally, there was a Treatment effect in regard to the velocity as the Stress group is shown to have higher velocity compared to the Control group $\mathrm{F}_{(1,126)}=78.022$, $\mathrm{p}<0.001$, refer to Figure 9. There was also a 3-way interaction between Treatment, Sex, Genotype and velocity $\mathrm{F}_{(1,126)}=3.825, \mathrm{p}=0.053$. Following Bonferroni-pairwise comparison as following up analysis, it was shown that Stress female KO and WT have higher velocity than their Control counterparts, $\mathrm{F}_{(1,126)}=20.413, \mathrm{p}<0.001$ and $\mathrm{F}_{(1,126)}=7.313, \mathrm{p}=0.008$ respectively. Also, the same was found in the males as the Stress male KO and WT are shown to have higher velocity compared to their Control counterparts $F_{(1,126)}=18.786$, $\mathrm{p}<0.001$ and $\mathrm{F}_{(1,126)}=36.719, \mathrm{p}<0.001$ respectively. 


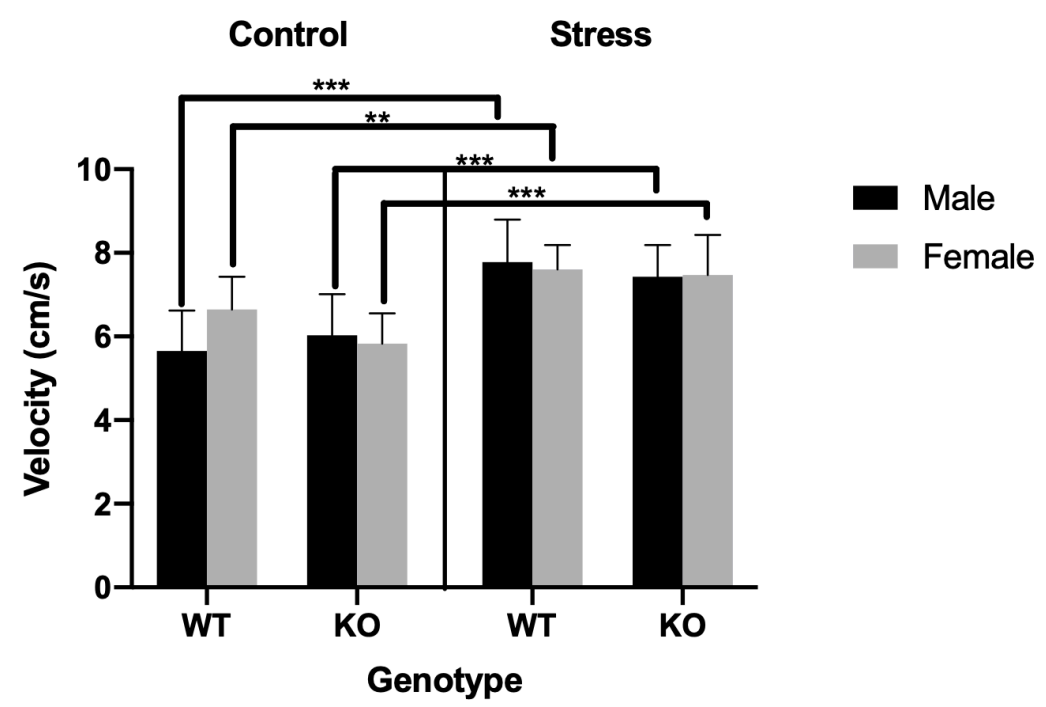

Figure 9. OFT: Velocity $(\mathrm{cm} / \mathrm{s})$.

Both Stress female KO and Stress female WT mice had significantly higher velocity compared to their Control counterparts $\mathrm{F}_{(1,126)}=20.413$, $\mathrm{p}<0.000$ and $\mathrm{F}_{(1,126)}=7.313$, $\mathrm{p}=0.008$, respectively. Stress male KO mice and Stress male WT mice also had significantly higher velocity than their Control counterparts $F_{(1,126)}=18.786, p<0.001$ and $F_{(1,126)}=36.719$, $\mathrm{p}<0.001$, respectively.

\section{TrkB.FL expression in the Amygdala}

TrkB.FL protein levels as well as ratio between the phosphorylated TrkB (pTrkB.FL) and unphosphorylated TrkB were analyzed using multivariate ANOVA. A significant main effect was evident between Sex and fully glycosylated $\operatorname{TrkB}\left(\mathrm{F}_{(1,32)}=6.418, \mathrm{p}=0.016\right)$ as well as partially glycosylated $\operatorname{TrkB}\left(\mathrm{F}_{(1,32)}=4.829, \mathrm{p}=0.035\right)$. The following indicates that the TrkB receptor is significantly higher in females than males, refer to Figures 10 and 11. There was no main effect regarding Treatment groups (Stress and Control) nor Genotype (KO and WT). Interestingly, there was a significant main effect between Sex and the ratio of pTrkB.FL and TrkB.FL, as the top band (fully glycosylated) and the bottom band (partially glycosylated $)$ were shown to be significant, $\left(F_{(1,32)}=5.270, p=0.028\right)$ and $\left(F_{(1,32)}=4.608\right.$, $\mathrm{p}=0.040$ ) respectively. A further assessment of the ratios between $\mathrm{pTrkB}$ and $\operatorname{TrkB}$ using 
Bonferroni-adjusted pairwise comparisons, it showed that female Stress WT mice have lower pTrkB:TrkB ratio (partially glycosylated receptor) compared to male Stress WT mice $\left(F_{(1,32)}=4.891, p=0.034\right)$. Additionally, Stress male WT mice had significantly higher ratio compared to Control male WT mice $\left(\mathrm{F}_{(1,32)}=8.562, \mathrm{p}=0.006\right)$, refer to Figure 15 . This was also evident in the fully glycosylated pTrkB:TrkB ratio as female Stress WT mice was

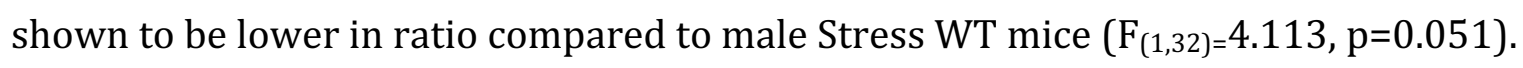

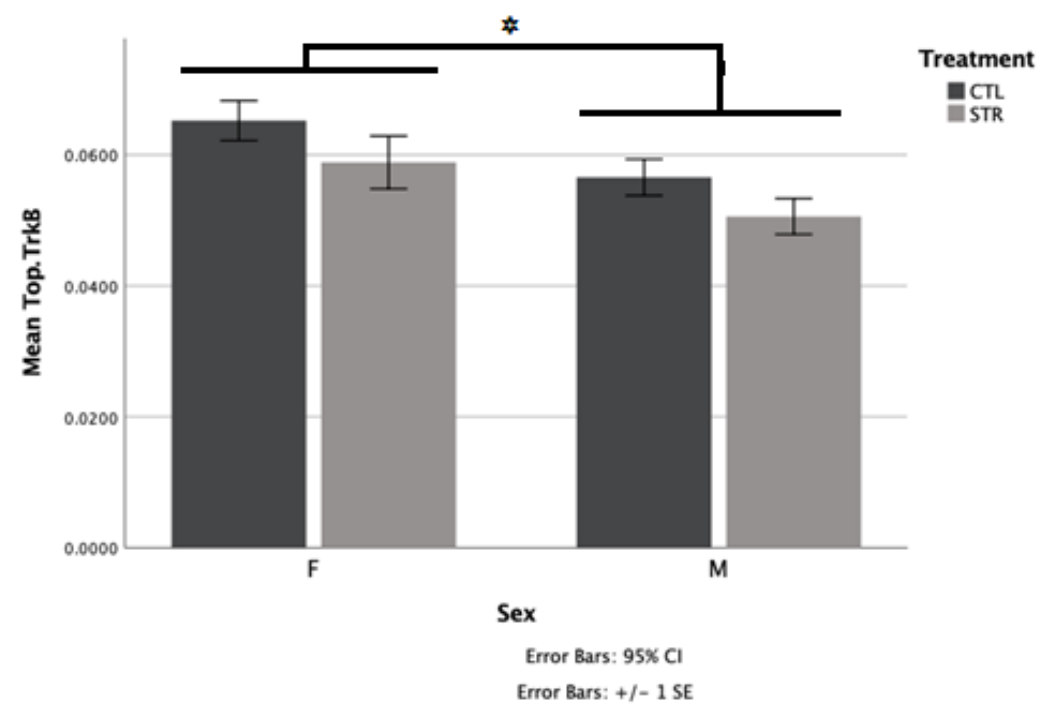

Figure 10. Fully glycosylated TrkB.FL by Sex and Treatment.

Females had significantly higher fully glycosylated TrkB.FL in Amygdala compared to males $\mathrm{F}_{(1,32)}=6.418, \mathrm{p}=0.016$. 


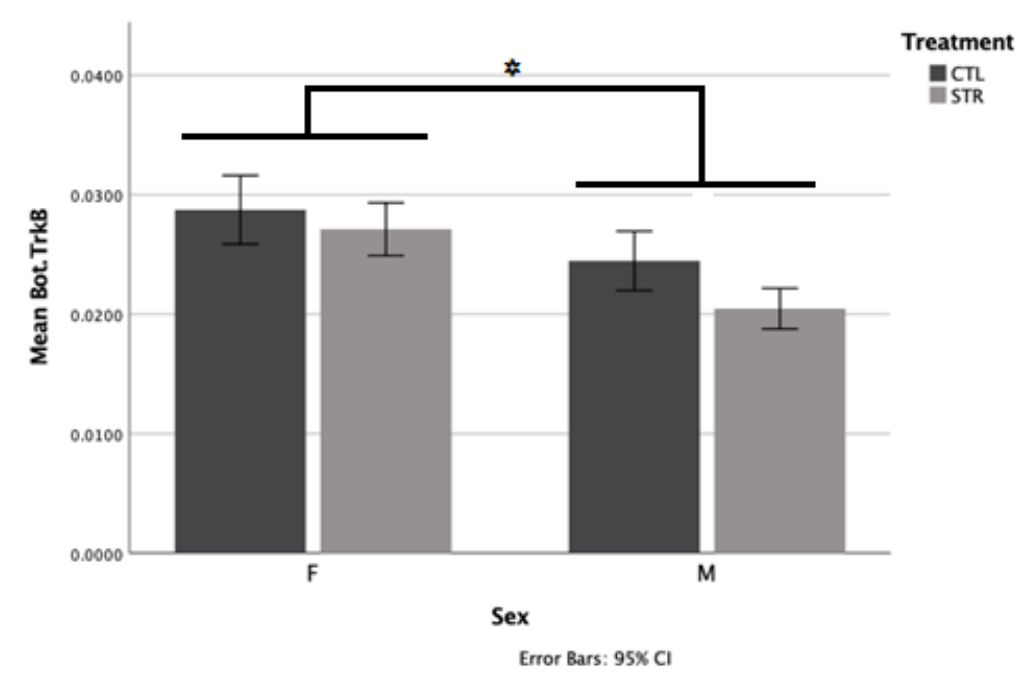

Figure 11. Partially glycosylated TrkB.FL by Sex and Treatment.

Females had significantly higher partially glycosylated TrkB.FL compared to males $\mathrm{F}_{(1,32)}=4.829, \mathrm{p}=0.035$.

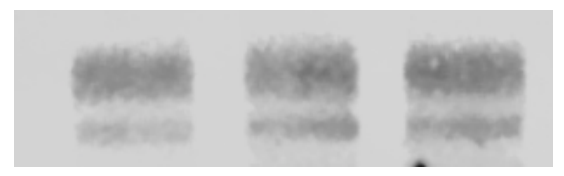

Figure 12. Western blot of TrkB.FL (BD610101 antibody).

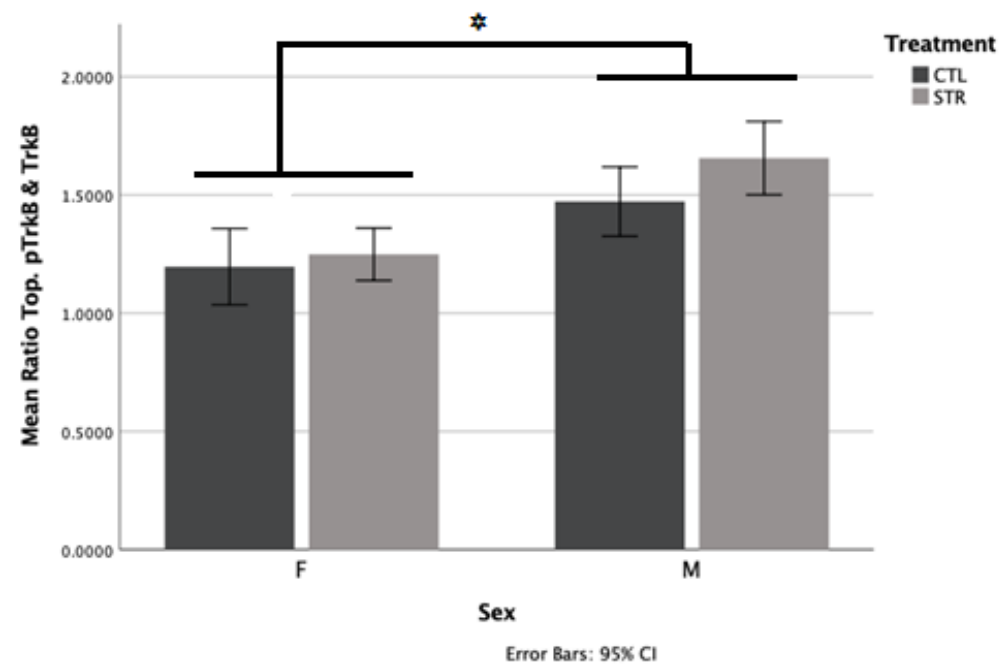

Figure 13. Ratio of fully glycosylated p.TrkB.FL and TrkB.FL by Sex and Treatment. 
Females had significantly lower ratio of fully glycosylated pTrkB.FL and TrkB.FL compared to males $\mathrm{F}_{(1,32)}=5.270$, $\mathrm{p}=0.028$.

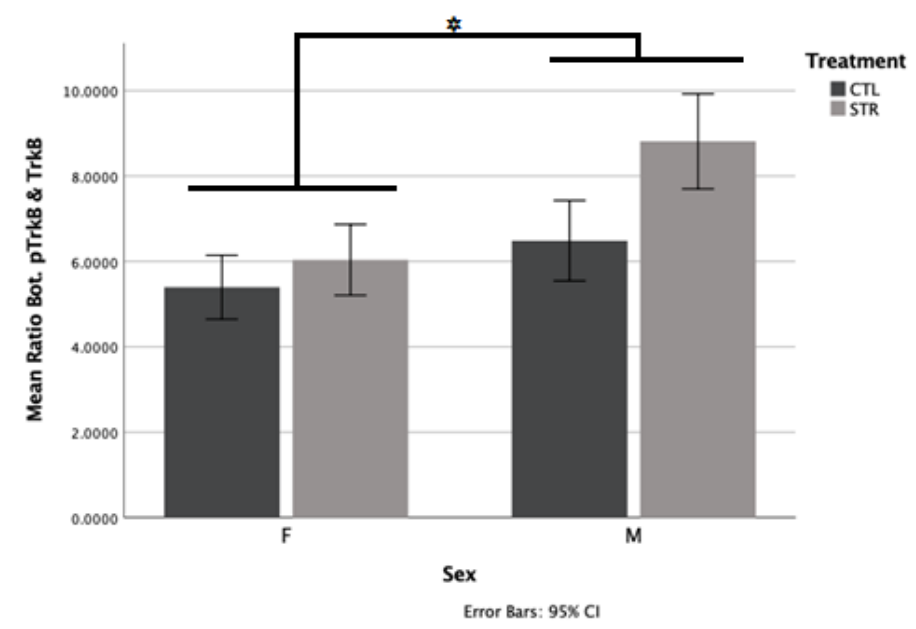

Figure 14. Ratio of partially glycosylated pTrkB.FL and TrkB.FL by Sex and Treatment.

Females had significantly lower ratio of partially glycosylated pTrkB.FL and TrkB.FL compared to males $\mathrm{F}_{(1,32)}=4.608$, $\mathrm{p}=0.040$.

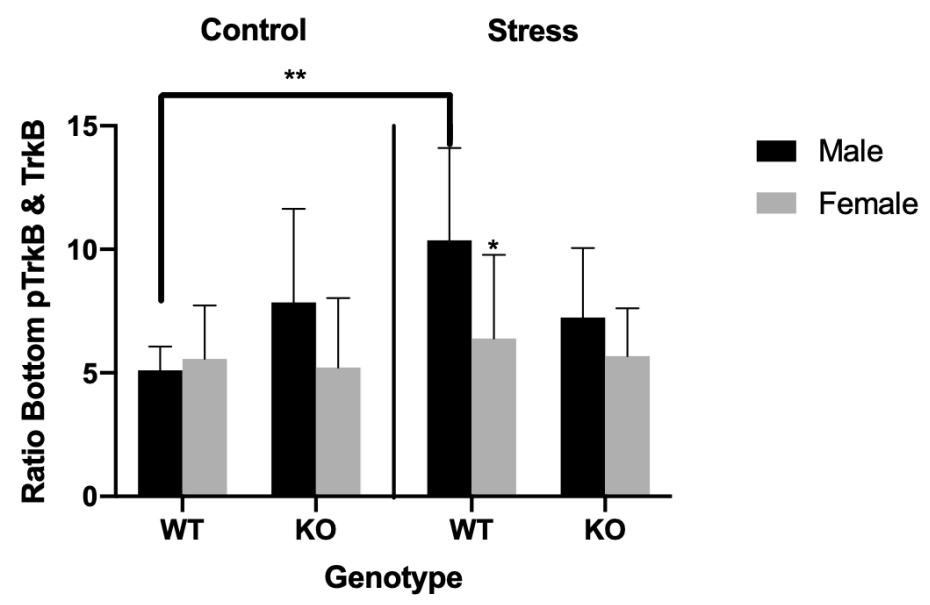

Figure 15. Ratio of partially glycosylated pTrkB.FL and TrkB.FL by Treatment, Genotype and Sex.

Stress WT females had significantly lower pTrkB.FL:TrkB.FL ratio compared to Stress WT males $\mathrm{F}_{(1,32)}=4.891$, $\mathrm{p}=0.034$. Stress male WT mice had higher pTrkB.FL:TrkB.FL ratio compared to Control male WT mice $\mathrm{F}_{(1,32)}=8.562$, $\mathrm{p}=0.006$. 


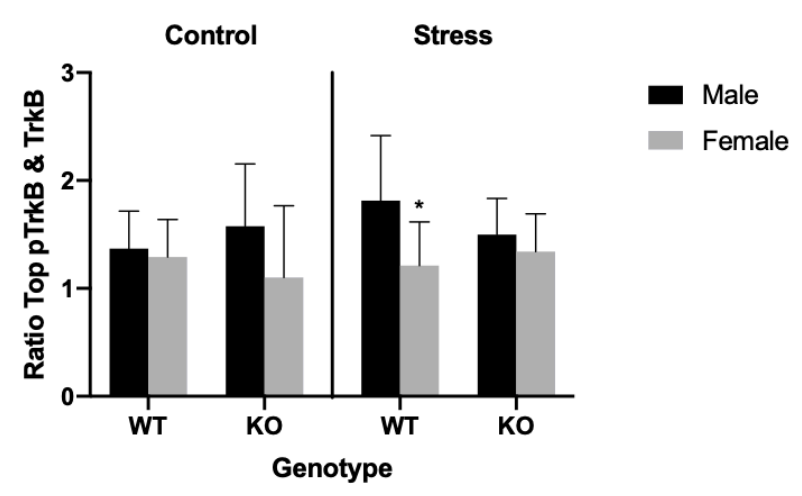

Figure 16. Ratio of fully glycosylated pTrkB.FL and TrkB.FL by Treatment, Genotype and Sex.

Stress female WT mice had significantly lower pTrkB.FL:TrkB.FL ratio compared to Stress

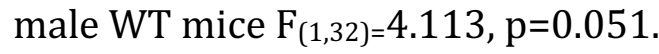
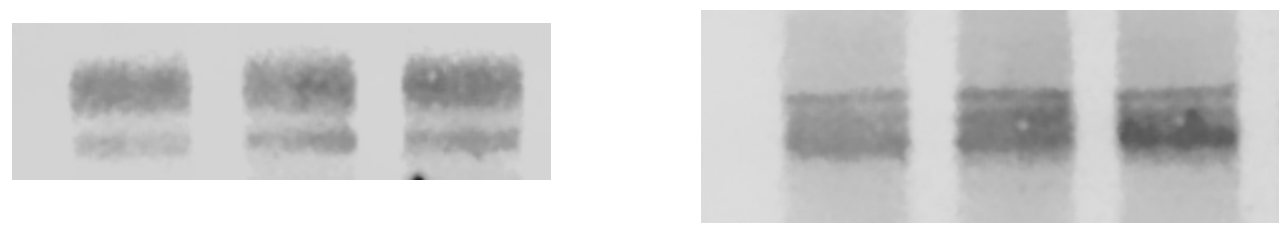

Figure 17. Western blot of Unphosphorylated TrkB.FL (left image - 1:1000BD610101 Rabbit antibody) and Phosphorylated TrkB.FL (right image - 1:1000 ABN1381 Mouse).

\section{Discussion}

While BDNF and its primary receptor, TrkB, have received substantial attention with regards to depression and anxiety (Martinowich et al., 2007), little work has focused upon the truncated, TrkB.T1 form of the receptor. Consequently, the purpose of this study is to evaluate the impact of knocking out TrkB.T1 receptor following with chronic unpredictable stress and evaluate its effect on the gut microbiota configuration and anxiety behavior. Curiously, the stressor exposure increased exploration of the center of an open 
field arena. Accordingly, to the typical interpretation of this test, this outcome suggests a reduction in anxiety with the stressor exposure, but the stress group also had greater total distance compared to controls, suggesting hyperlocomotion. It could be that the stressed mice had a "manic-like" behavior as they were shown to be hyperactive. Similarly, hyperactivity was seen in a study conducted to block TrkBCaMKII-CRE in the forebrain in which these mice exhibited hyperlocomotion as well as impulsive behavior rather than seeing a typical depression-like symptom where there would be a decrease in the locomotion as well as impulsive behavior (Zörner et al., 2003). Interestingly, male mice exhibited these behavioral changes to a greater extent than females, indicates sex-dependent modulation of the stressor impact. Yet, genotype had no effect, indicating that our data do not support a major role for TrkB.T1 in anxiety responses to a chronic unpredictable stressor regimen. Though many research studies argue that a typical anxiety/depressive like symptom are reflected in a lack of entries to the center zone of the open field apparatus, there also may be atypical symptoms associated with depression and anxiety in which the opposite symptoms would rise. Again, the velocity at which the mice travelled were also shown to be higher in the stressed mice, which is a marker for hyperactivity. There might also be another explanation, such that our choice of stressor might impact habituation levels to the open field. Indeed, the control mice may have experienced the open field itself as a stressful event, whereas the stress group habituated to experiencing chronic stress that the open field test was not as stressful compared to the other stressors they have experienced.

The expression of the TrkB.FL was also investigated in an attempt to assess how it is influenced by the chronic stress exposure, as well as investigate if TrkB.T1 knockout will 
influence its expression in the amygdala. We focused upon the amygdala given its important role in mediated anxiety and also the fact that previous reports indicated that BDNF influence signaling in this brain region (Yee et al., 2007; Marle et al., 2009; Etkin \& Wager, 2007; Lonsdorf et al., 2010; Chhatwal et al., 2006; Rattiner et al., 2004; Andero et al., 2011). The majority of the studies that have assessed BDNF in the amygdala, have found that the receptor TrkB increases in phosphorylation specifically during the consolidation period (which is suggested to be due to the release of BDNF) in response to Pavlovian fear conditioning stressors (Rattiner et al., 2004, 2005; Yee et al., 2006). Also, interestingly, prelimbic cortex BDNF levels have downstream effects through TrkB receptor on memory consolidation specifically in the amygdala but has no effect in the extinction of fear. Specifically, prelimbic BDNF knockdown mice had attenuated response to fear after fearconditioning, but when exposed to systemic TrkB agonist, 7,8-dihydroxyflavone, the attenuation of fear was alleviated (Choi et al., 2012). Additionally, TrkB receptor increases in phosphorylation during consolidation period when exposed to Pavlovian fear conditioning. This suggests that the activation of the TrkB receptor is subsequent to BDNF release in the amygdala (Rattiner et al., 2004). This may be relevant for the present study in that understanding how different TrkB isoforms can have different functions and different effects on the fear related aspect of the amygdala. Our present study knocked out TrkB.T1 receptor isoform to see its impact on the TrkB.FL receptor. We also had a stress group that did not have the TrkB.T1 receptor knocked out to see if the CUS will have a solo impact on the TrkB.FL expression in the amygdala. 
Intriguingly, we found sex differences in TrkB.FL levels, such that females had significantly higher TrkB.FL expression in the amygdala compared to male mice (Figure 13). This was also evident in the partially glycosylated TrkB.FL receptor expression as the females were shown to have higher protein content than males (Figure 11). It should also however be noted that stressed mice had lower expression levels than controls. This is somewhat consistent with another study performed by Bland et al., 2005 as they showed sex differences in regard to acute uncontrollable/inescapable stress in rat model as their control group showed higher BDNF levels in the prefrontal subregions (anterior cingulate, prelimbic, infralimbic and ventral orbital) in females compared to male rats. On the other hand, their male rats showed higher BDNF levels in the prefrontal subregions when exposed to inescapable stress then immediately sacrificed (Bland et al., 2005). Additionally, maltreatment including stress delivered in depression models provoked an increase in BDNF expression in female but not male rats in the amygdala region (Hill et al., 2014). It also seems that estrogen may play a role in gender related differences as estrogen is suggested to induce BDNF transcription through enhancing CREB activity as well as elevating the methylation of BDNF promoter (Zhou et al., 2005). The CREB activity is suggested to be one major transcription factor to influence BDNF availability in neurons through $\mathrm{Ca}^{2+}$ extracellular influx (Tao et al., 1998). In addition, BDNF seems to be affected by estradiol as the induction of estradiol seemed to be elevated BDNF mRNA levels in the hippocampus (CA3, CA4 and dentate gyrus). This suggests that estradiol hormone is required for BDNF expression in certain regions (Singh et al., 1995). 
Our findings could be at least, in part, due to the interaction of $\mathrm{GABA}_{\mathrm{A}}$ receptors as it has been shown that TrkB is one of the main pathways that lead to the internalization of $\mathrm{GABA}_{\mathrm{A}}$ receptors which plays a role in the hyperactivity of amygdala during fear memory reconsolidation (Andero et al., 2014). A decrease in the TrkB protein is suggested to decrease the tonic/phasic inhibition in amygdala which results in a heightened excitatory drive. Another study also suggested that the consolidation fear memory period in the amygdala occurs due to the increase in TrkB phosphorylation (activated) expression (Rattiner et al., 2004). With this said, it could be that the lack of the TrkB.T1 receptor in the present study played a role in the internalization of $\mathrm{GABA}_{\mathrm{A}}$ receptors. Yet it is not fully understood as to why the WT mice did not show an increased TrkB receptor expression.

Besides absolute TrkB.FL levels, it also is useful to look at the ratio between its phosphorylated and non-phosphorylated forms. Indeed, Woo et al., 2012 found lower pTrkB:TrkB ratio in females with $5-\mathrm{HT}_{1} \mathrm{~A}^{-/-}$mice as well as $5-\mathrm{HT}_{1} \mathrm{~A}^{-/-} / \mathrm{BDNF}^{+/-}$mice in the hippocampus, but not in male mice. Phosphorylation at different sites on the TrkB receptor seem to play different roles. For example, phosphorylation at Y515 residue was shown to activate MAPK and PI3K pathways. Point mutations in the Y515 residue was shown to produce issues/deficits in regard to the consolidation of fear conditioning. On the other hand, phosphorylation at Y816 residue was shown to activate CREB signaling pathways. Point mutations in the Y816 residue showed deficits in regard to the acquisition of fear conditioning (Mahan \& Ressler, 2012). This indicates that different phosphorylation sites in the TrkB receptor may have different effects on amygdala fear related processes. Our study specifically investigates the Y816 of the TrkB FL receptor. We looked at the ratio between 
phosphorylated Y816 receptor as well as the unphosphorylated TrkB FL receptor. To this end, we found that the females had significantly higher TrkB receptor expression compared to male mice, and females had lower pTrkB:TrkB ratio compared to males. Sex differences have been shown in several studies, as females have higher TrkB receptor expression in amygdala and forebrain compared to males while males have higher TrkB expression in the hippocampus (Liu et al., 2014; Snigdha et al., 2011; Bakos et al., 2009).

In regard to the microbiota configuration pre and post chronic unpredictable stress, there were no significant differences between any of the groups. This was somewhat surprising since many studies found that Lactobacillus rhamnosus, Bifidobacterium longum, and Bifidobacterium breve all seem to be affected by anxiety and depressive models (Osadchiy et a., 2019; Froster \& Neufled, 2013; Clapp et al., 2017; Park et a., 2013). Further research has shown that SNPs (single-nucleotide polymorphisms) is what has been shown to influence the gut microbiota configuration (Bleckman et a., 2015). In this regard, C57BL/6j mice are shown to have an inactive a toll-like receptor-10 (TLR-10), as C57BL/6j mice have been shown to have a pseudogene rather than an active gene which is shown to be an active gene in humans (Mestas et al., 2004). TLR-10 is an immune receptor which is shown to have an anti-inflammatory response rather than pro-inflammatory response on human primary cells as it was shown to suppress B cell proliferation as well as cytokine production (Hess et al., 2017). Studies involving stress paradigms with depression and anxiety-like related behaviors and how the gut microbiota influenced these have been conducted mainly using BALB/c strain mice and GF versus SPF mice rather than the C57BL/6j mice that we currently used (Zheng et al., 2016; Dinel et al., 2019). Therefore, 
perhaps using one of these strains (BALB/c or GF/SPF mice) would have shown to produce sufficient gut microbiota shift due to chronic stress. The changes in the bacterial strains such as bifidobacteria, lactobacillus, and streptococcus are mainly shown on GF mice or BALB/c mice rather than C57BL/6j mice (Desbonnet et al., 2008; Lyte $t$ al., 2011; McVey Neufeld et al., 2018). Therefore, it would be suggested to use BALB/c mice rather than C57BL/6j mice in order to test how the gut microbiota is influenced from chronic stress.

To the best of our knowledge, this is the first study that assessed how chronic unpredictable stress influences anxiety outcomes in TrkB.T1 KO mice. In particular, we provide evidence that TrkB.T1 KO mice do not differ in their anxiety -like behavior nor was the microbiome or amygdaloid TrkB.FL levels altered. However, we did demonstrate that female mice had higher TrkB.FL expression in the amygdala compared to male mice, but the ratio between pTrkB.FL \& TrkB was shown to be lower in females than males. Further studies are suggested to investigate the effect of TrkB.T1 KO on additional indices of anxiety and depression. 


\section{Appendix A}

\section{Gut microbiota configuration}

The gut microbiota was examined in order to see if chronic unpredictable stress has an impact on the gut flora of the Stress mice versus Control mice. Additionally, genotypic differences and sex differences were also taken into account. It seems that there is no significant difference in any of the treatment groups, genotypic groups nor sex differences. As illustrated in figure 19, the bar-plot does not show any patterns that would naturally be shown if there is a switch in the gut flora between all variable groups.

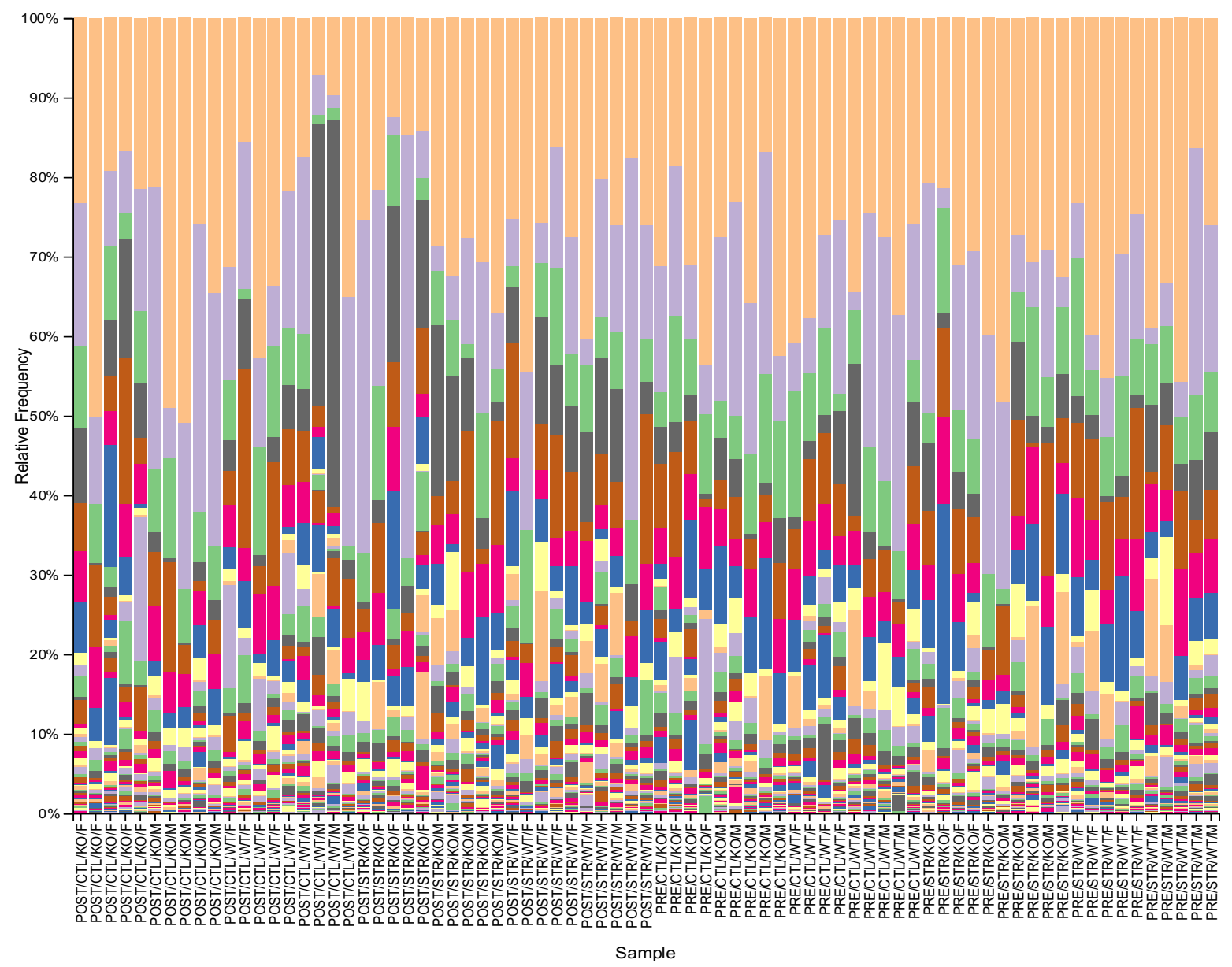

Figure 18: Taxa Bar-plot (Taxonomic level 6).

A Bar-plot of the gut microbiota showing no patterns. Neither Treatment, Genotype, nor Sex seem to be shown to have an influenced the gut flora in this strain of mice. 
D_0_Bacteria;D_1_Bacteroidetes;D_2_Bacteroidia;D_3_Bacteroidales;D_4_Muribaculaceae; D_5_uncultured_bacterium

D_O_Bacteria;D_1_Bacteroidetes;D_2_Bacteroidia;D_3_Bacteroidales;D_4_Muribaculaceae;D_5_uncultured_Bacteroidales_bacter

D_O_Bacteria; D_1__Bacteroidetes;D_2_Bacteroidia; D_3_Bacteroidales;D_4_Muribaculaceae;

D_O_Bacteria;D_1_Firmicutes;D_2_Clostridia;D_3_Clostridiales;D_4_Lachnospiraceae;D_5_Lachnospiraceae_NK4A136_group

D_0_Bacteria; D_1_Bacteroidetes; D_2__Bacteroidia; $D$ _3__Bacteroidales; D_4_Bacteroidaceae; $D$ _5_Bacteroides

D_O_Bacteria; D_1_Bacteroidetes; D_2_Bacteroidia; D_3_Bacteroidales;D_4_Muribaculaceae;Ambiguous_ta

D_O_Bacteria;D_1_Firmicutes;D_2__Bacilli; D_3_Lactobacillales; D_4_Lactobacillaceae;D_5_Lactobacillus

D_O_Bacteria;D_1_Bacteroidetes;D_2__Bacteroidia;D_3_Bacteroidales;D_4_Prevotellaceae;D_5_Prevotellaceae_UCG-001

D_o_Bacteria; D_1_Firmicutes;D_2 _Erysipelotrichia; D_3_Erysipelotrichales;D_4_Erysipelotrichaceae;D_5_Faecalibaculum

D_0_Bacteria; D_1_Bacteroidetes;D_2_Bacteroidia;D_3_Bacteroidales;D_4__Prevotellaceae;D_5_Alloprevotella

D_0_Bacteria;D_1_Bacteroidetes;D_2_Bacteroidia;D_3__Bacteroidales;D_4_Rikenellaceae;D_5_Alistipes

D_O_Bacteria;D_1_Bacteroidetes;D_2_Bacteroidia; D_3_Bacteroidales;D_4_Muribaculaceae;D_5_Muribaculum

D_o_Bacteria;D_1_Firmicutes;D_2__Clostridia;D_3_Clostridiales;D_4_Lachnospiraceae; D_5__uncultured

D_o_Bacteria;D_1_Bacteroidetes;D_2__Bacteroidia;D_3_Bacteroidales;D_4_Rikenellaceae;D_5_Rikenellaceae_RC9_gut_group

D_O_Bacteria; D_1_Firmicutes;D_2_Clostridia;D_3_Clostridiales; D_4_Ruminococcaceae;D_5_Caproiciproducens

D_O_Bacteria; D_1__Bacteroidetes; D_2__Bacteroidia; D_3_Bacteroidales; D_4_Tannerellaceae;D_5_Parabacteroides

D_o_Bacteria;D_1 Bacteroidetes;D_2 Bacteroidia; D_3__Bacteroidales;D_4_Prevotellaceae;D_5_Paraprevotella

D_o_Bacteria;D_1_Firmicutes;D_2__Clostridia;D_3_Clostridiales;D_4_Lachnospiraceae;

D_O_Bacteria; D_1_Firmicutes;D_2_Clostridia;D_3_Clostridiales;D_4_Lachnospiraceae;D_5_tTyzzerella_3

D_o_Bacteria;D_1_Firmicutes;D_2_Clostridia;D_3_Clostridiales;D_4_Lachnospiraceae;D_5_LLachnoclostridium

D_o_Bacteria;D_1_Firmicutes;D_2_Clostridia;D_3_Clostridiales;D_4_Ruminococcaceae:

D_O_Bacteria;D_1__Firmicutes;D_2__Clostridia;D_3_Clostridiales;D_4_Lachnospiraceae;D_5_LLachnospiraceae_UCG-001

D_O_Bacteria;D_1_Bacteroidetes;D_2_Bacteroidia;D_3_Bacteroidales;D_4_Marinifilaceae;D_5_Odoribacter

D_o_Bacteria;D_1_Firmicutes;D_2__Clostridia;D_3_Clostridiales;D_4_Ruminococcaceae;D_5_Ruminococcaceae_UCG-014

D_O_Bacteria;D_1__Firmicutes;D_2_Clostridia;D_3_CClostridiales;D_4_Ruminococcaceae:D_5_Oscillibacter

D_O_Bacteria; D_1__Bacteroidetes;D_2__Bacteroidia;D_3 Bacteroidales;D_4_Rikenellaceae;D_5_Rikenella

D_O_Bacteria;D_1__Firmicutes;D_2_Clostridia;D_3_Clostridiales;D_4_LLachnospiraceae;D_5_[Eubacterium] xylanophilum group

D_0_Bacteria;D_1_Firmicutes;D_2 _Clostridia;D_3 Clostridiales;D_4_Ruminococcaceae;D_5 Ruminiclostridium_9

D_o_Bacteria;D_1_Epsilonbacteraeota;D_2 _Campylobacteria;D_3_Campylobacterales;D_4_Helicobacteraceae;D_5_Helicobacter

D_O Bacteria:D 1 Proteobacteria:D_2 Gammaproteobacteria:D_3 Betaproteobacteriales:D 4 Burkholderiaceae;D 5 Parasutter

D_o_Bacteria;D_1_Firmicutes;D_2_Clostridia;D_3_Clostridiales;D_4_Lachnospiraceae; D 5 Roseburia

D_o_Bacteria;D_1_Firmicutes;D_2__Clostridia;D_3_Clostridiales;D_4_Ruminococcaceae;D_5_Ruminiclostridium

D_O_Bacteria; D_1_Firmicutes;D_2_Clostridia;D_ 3 Clostridiales;D_4_Lachnospiraceae;D 5 Lachnospiraceae UCG-006

D_O_Bacteria;D_1_Firmicutes;D_2_Clostridia;D_3_Clostridiales;D_4_Clostridiales_vadinBB60_group;D_5_uncultured_bacterium

D_O_Bacteria; D_1__Proteobacteria;D_2_Deltaproteobacteria;D_3_Desulfovibrionales; D_4_Desulfovibrionaceae; D_5_uncultured

D_0_Bacteria;D_1_Firmicutes;D_2__Clostridia;D_3_Clostridiales;D_4_Clostridiales_vadinBB60_group;Ambiguous_taxa

D_O_Bacteria; D_1_Proteobacteria;D_2_Deltaproteobacteria;D_3_Desulfovibrionales; D_4_Desulfovibrionaceae;D_5_Desulfovibrio

D_O Bacteria:D 1 Firmicutes:D 2 Clostridia:D 3 Clostridiales:D 4 Clostridiales_vadinBB60 group:

D_O_Bacteria; D_1_Actinobacteria;D_2_Actinobacteria;D_3_Bifidobacteriales; D_4__Bifidobacteriaceae;D_5_Bifidobacterium

D_o__Bacteria;D_1_Firmicutes;D_2__Clostridia;D_3_Clostridiales;D_4__Peptococcaceae;D_5_uncultured

D_O_Bacteria;D_1_Firmicutes;D_2_Erysipelotrichia; D_3_Erysipelotrichales; D_4_Erysipelotrichaceae;D_5_Turicibacter

D_O_Bacteria; D_1_Firmicutes;D_2_CClostridia;D_3_Clostridiales;D_4_Clostridiaceae_1;D_5_Clostridium_sensu_stricto_1

D_O_Bacteria; D_1_Firmicutes;D_2_Clostridia;D_3_Clostridiales;D_4__Peptostreptococcaceae;D_5__Ro

D_O_Bacteria; D_1__Firmicutes;D_2__Clostridia;D_3_Clostridiales;D_4__Lachnospiraceae;D_5__ASF356

D_o Bacteria; D_1 Firmicutes;D_2 Clostridia;D_3 Clostridiales;D_4_Lachnospiraceae;D_5__Blautia

D_o Bacteria;D_1 Firmicutes;D 2 Clostridia;D_ 3 Clostridiales;D_4_Lachnospiraceae; D 5_[Eubacterium]ventriosum_group

D_o_Bacteria;D_1_Firmicutes;D_2_Clostridia;D_3_Clostridiales;D_4_Ruminococcaceae;D_5_Intestinimonas

D o Bacteria;D 1 Firmicutes;D 2 Erysipelotrichia; D 3 Erysipelotrichales;D 4 Erysipelotrichaceae;D 5 Erysipelatoclostridium

D_O_Bacteria;D_1_Firmicutes;D_2_Clostridia;D_3_Clostridiales;D_4__Ruminococcaceae;D_5_Ruminococcaceae_NK4A2 14_group

D___Bacteria;D_1_Firmicutes;D_2_Clostridia;D_3_Clostridiales;D_4_Ruminococcaceae;D_5_Anaerotruncus

D_O_Bacteria;D_1_Actinobacteria;D_2_CCoriobacteriia;D_3_Coriobacteriales; D_4_Eggerthellaceae; D_5_Enterorhabdus

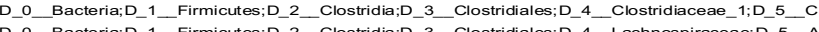

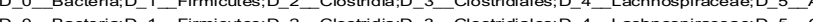

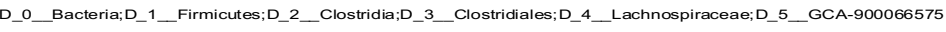

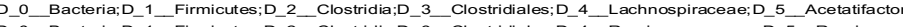

aceae_UCG-013

D_o Bacteria;D 1 Firmicutes; D 2 C Clostridia;D 3 Clostridiales; D 4 L Lachnospiraceae; D 5 - Tyzzerella

D_O_Bacteria;D_1_Firmicutes;D_2_Clostridia;D_3_Clostridiales;D_4_Family_XIII;D_5__Family_XIII_UCG-00

_ o Bacteria; D 1 Firmicutes:D _ Clostridia_D_ 3 Clostridiales:__ 4_Ruminococcaceae; D 5 [Eubacterium] coprostanoligenes gr

D_o_Bacteria;D_1_Firmicutes;D_2_Clostridia;D_3_Clostridiales;D_4_Ruminococcaceae;D_5_uncultured

D_o_Bacteria;D_1_Proteobacteria;D_2__Alphaproteobacteria;D_3_Rhizobiales;D_4_Rhizobiaceae; D_5_Allorhizobium-Neorhizobiun

D_0_Bacteria;D_1_Firmicutes;D_2__Erysipelotrichia;D_3_Erysipelotrichales;D_4_Erysipelotrichaceae;D_5_Candidatus_Stoquefichu

D_0_Bacteria;D_1__Firmicutes;D_2__Clostridia;D_3_Clostridiales;D_4_Family_XIII;D_5_[Eubacterium]_brachy_group

D_o__Bacteria;D_1_Firmicutes;D_2__Clostridia;D_3_Clostridiales;D_4_Ruminococcaceae;D_5_Butyricicoccus

D_o_Bacteria;D_1_Firmicutes;D_2_Clostridia;D_3_Clostridiales;D_4_Family_XIII;D_5_[Eubacterium]_nodatum_group

D_O_Bacteria; D_1__Firmicutes;D_2_Clostridia;D_3_Clostridiales;D_4_Ruminococcaceae;D_5_Ruminococcaceae_UCG-010

D_O_Bacteria; D_1_Actinobacteria;D_2_Coriobacteriia;D_3_Coriobacteriales;D_4_Atopobiaceae; D_5_CCoriobacteriaceae_UCG-002

D_o_Bacteria; D_1_Firmicutes;D_2_Erysipelotrichia;D_3_Erysipelotrichales;D_4__Erysipelotrichaceae;

D_0_Bacteria;D_1_Firmicutes;D_2_Clostridia;D_3_Clostridiales;D_4_Ruminococcaceae;D_5_Ruminococcus_

D_O_Bacteria; D_1_Firmicutes;D_2_Clostridia;D_3_Clostridiales;D_4_Lachnospiraceae;D_5__Anaerostipes

D_o_Bacteria;D_1_Firmicutes;D_2_Clostridia;D_3_Clostridiales;D_4_Ruminococcaceae;D_5_GCA-900066225

D_o_Bacteria;D_1_Firmicutes;D_2_Clostridia;D_3_Clostridiales;D_4_Ruminococcaceae;D_5_Ruminococcaceae UCG-003

D_0_Bacteria;D_1_Firmicutes;D_2_CClostridia;D_3_Clostridiales;D_4_Peptococcaceae;D_5_Peptococcus

D_o_Bacteria;D_1__Firmicutes;D_2__Clostridia;D_3_Clostridiales;D_4_Peptostreptococcaceae;D_5_Clostridioides

D_o_Bacteria;D_1__Firmicutes;D_2__Clostridia;D_3_Clostridiales;D_4_LLachnospiraceae;D_5_Marvinbryantia

D_o_Bacteria;D_1__Proteobacteria;D_2_Deltaproteobacteria;D_3_Desulfovibrionales;D_4__Desulfovibrionaceae;D_5_Bilophila

D_o B Bacteria;D_1_Firmicutes;D_2_CClostridia;D_3_Clostridiales;D_4_Lachnospiraceae; D_5_LLachnospiraceae_FCSO20_group

D_o_Bacteria;D_1__Firmicutes;D_2__Bacilli;D_3_LLactobacillales;D_4_Streptococcaceae;D_5_Streptococcus

D_o_Bacteria;D_1_Firmicutes;D_2__Clostridia;D_3_Clostridiales;D_4__Ruminococcaceae;D_5_Ruminiclostridium_6

D_0_Bacteria;D_1 Firmicutes;D_2__Clostridia;D_3_Clostridiales;D_4__Ruminococcaceae;D_5_Ruminococcus_2

D_o Bacteria; D 1 Cyanobacteria; D 2 Melainabacteria,D 3 Gastranaerophilales:Ambiguous taxa;Ambiguous taxa

D_O__Bacteria;D_1_Proteobacteria;D_2_Gammaproteobacteria;D_3__Pseudomonadales;D_4__Pseudomonadaceae;D_5_Pseudomol

D_o Bacteria; D_1 Proteobacteria;D_2 Gammaproteobacteria;D_3 Betaproteobacteriales;D_4 Burkholderiaceae;D_5_Rhodofera

D_O_Bacteria;D_1__Firmicutes;D_2__Clostridia;D_3_Clostridiales;D_4_Ruminococcaceae;D_5_Harryflintia

D_o _Bacteria;D_1__Firmicutes:D_2 Bacilli:D_3 Lactobacillales;D_4 Enterococcaceae; D_5 _Enterococcus

D_o Bacteria; D 1 Firmicutes;D 2 Bacilli; D 3 Lactobacillales:D 4 Leuconostocaceae; D 5 Weissella

D_0_Bacteria; D_1__Firmicutes;D_2__Bacilli;D_3__Bacillales;D_4__Staphylococcaceae;D_5_Staphylococcus

D_O_Bacteria; D_1__Tenericutes;D_2__Mollicutes;D_3_Mycoplasmatales;D_4_Mycoplasmataceae;D_5_Ureaplasma

D_0_Bacteria;D_1__Firmicutes;D_2_Clostridia;D_3_Clostridiales;D_4_Ruminococcaceae;D_5_Flavonifractor

\section{Figure 19: List of bacteria and their color coordinate.}

The following is a list of the bacterial strains with their specific color that is shown in the barplot shown in figure 19. 


\section{References}

Adamec, R., Hebert, M., Blundell, J., \& Mervis, R. F. (2012). Dendritic morphology of amygdala and hippocampal neurons in more and less predator stress responsive rats and more and less spontaneously anxious handled controls. Behavioural Brain Research, 226(1), 133-146.

Ait-Belgnaoui, A., Colom, A., Braniste, V., Ramalho, L., Marrot, A., Cartier, C., Houdeau, E., Theodorou, V., \& Tompkins, T. (2014). Probiotic gut effect prevents the chronic psychological stress-induced brain activity abnormality in mice.

Neurogastroenterology and Motility, 26(4), 510-520.

Almaguer-Melian, W., Mercerón-Martínez, D., Pavón-Fuentes, N., Alberti-Amador, E., LeonMartinez, R., Ledón, N., Delgado Ocaña, S., \& Bergado Rosado, J. A. (n.d.). Erythropoietin Promotes Neural Plasticity and Spatial Memory Recovery in Fimbria-Fornix-Lesioned Rats. Neurorehabilitation and Neural Repair, 29(10), 979-988.

Andero, R., Choi, D. C., \& Ressler, K. J. (2014). BDNF-TrkB receptor regulation of distributed adult neural plasticity, memory formation, and psychiatric disorders. In Progress in molecular biology and translational science (Vol. 122, pp. 169-192). Academic Press.

Andero, R., Heldt, S. A., Ye, K., Liu, X., Armario, A., \& Ressler, K. J. (2011). Effect of 7, 8dihydroxyflavone, a small-molecule TrkB agonist, on emotional learning. American Journal of Psychiatry, 168(2), 163-172.

Anisman, H. (2014). An introduction to stress and health. Sage.

Babu, H. (2009). Synaptic network activity induces neuronal differentiation of adult hippocampal precursor cells through BDNF signaling. Frontiers in Neuroscience, 3(SEP), 1.

Bakos, J., Hlavacova, N., Rajman, M., Ondicova, K., Koros, C., Kitraki, E., ... \& Jezova, D. (2009). Enriched environment influences hormonal status and hippocampal brain derived neurotrophic factor in a sex dependent manner. Neuroscience, 164(2), 788-797.

Bandelow, B., Michaelis, S., \& Wedekind, D. (2017). Treatment of anxiety disorders. Dialogues in Clinical Neuroscience, 19(2), 93-106.

Barker, M. M., Beresford, B., Bland, M., \& Fraser, L. K. (2019). Prevalence and Incidence of Anxiety and Depression Among Children, Adolescents, and Young Adults With LifeLimiting Conditions. JAMA Pediatrics, 173(9), 835. 
Barnum, C. J., Pace, T. W. W., Hu, F., Neigh, G. N., \& Tansey, M. G. (2012). Psychological stress in adolescent and adult mice increases neuroinflammation and attenuates the response to LPS challenge. Journal of Neuroinflammation, 9, 9.

Barrientos, R. M., Sprunger, D. B., Campeau, S., Higgins, E. A., Watkins, L. R., Rudy, J. W., \& Maier, S. F. (2003). Brain-derived neurotrophic factor mRNA downregulation produced by social isolation is blocked by intrahippocampal interleukin-1 receptor antagonist. Neuroscience, 121(4), 847-853.

Bath, K. G., Jing, D. Q., Dincheva, I., Neeb, C. C., Pattwell, S. S., Chao, M. V, Lee, F. S., \& Ninan, I. (2012). BDNF Val66Met Impairs Fluoxetine-Induced Enhancement of Adult Hippocampus Plasticity. Neuropsychopharmacology, 37(5), 1297-1304.

Bathina, S., \& Das, U. N. (2015). Brain-derived neurotrophic factor and its clinical implications. Archives of Medical Science : AMS, 11(6), 1164-1178.

Beesdo, K., Knappe, S., \& Pine, D. S. (2009). Anxiety and Anxiety Disorders in Children and Adolescents: Developmental Issues and Implications for DSM-V. In Psychiatric Clinics of North America (Vol. 32, Issue 3, pp. 483-524). NIH Public Access.

Bistoletti, M., Caputi, V., Baranzini, N., Marchesi, N., Filpa, V., Marsilio, I., Cerantola, S., Terova, G., Baj, A., Grimaldi, A., Pascale, A., Frigo, G., Crema, F., Giron, M. C., \& Giaroni, C. (2019). Antibiotic treatment-induced dysbiosis differently affects BDNF and TrkB expression in the brain and in the gut of juvenile mice. PLOS ONE, 14(2).

Björkholm, C., \& Monteggia, L. M. (2016). BDNF - A key transducer of antidepressant effects. In Neuropharmacology (Vol. 102, pp. 72-79). Elsevier Ltd.

Bland, S. T., Schmid, M. J., Der-Avakian, A., Watkins, L. R., Spencer, R. L., \& Maier, S. F. (2005). Expression of c-fos and BDNF mRNA in subregions of the prefrontal cortex of male and female rats after acute uncontrollable stress. Brain Research, 1051(1-2), 90-99.

Boesmans, W., Gomes, P., Janssens, J., Tack, J., \& Berghe, V. (2008). Brain-derived neurotrophic factor amplifies neurotransmitter responses and promotes synaptic communication in the enteric nervous system. Gut, 57, 314-322.

Brachman, R. A., McGowan, J. C., Perusini, J. N., Lim, S. C., Pham, T. H., Faye, C., Gardier, A. M., Mendez-David, I., David, D. J., Hen, R., \& Denny, C. A. (2016). Ketamine as a Prophylactic Against Stress-Induced Depressive-like Behavior. Biological Psychiatry, 79(9), 776786.

Bravo, J. A., Forsythe, P., Chew, M. V, Escaravage, E., Savignac, H. M., Dinan, T. G., Bienenstock, J., Cryan, J. F., \& Designed, J. F. C. (n.d.). Ingestion of Lactobacillus strain regulates emotional behavior and central GABA receptor expression in a mouse via the vagus nerve. 
Carim-Todd, L., Bath, K. G., Fulgenzi, G., Yanpallewar, S., Jing, D., Barrick, C. A., Becker, J., Buckley, H., Dorsey, S. G., Lee, F. S., \& Tessarollo, L. (2009). Endogenous truncated TrkB.T1 receptor regulates neuronal complexity and TrkB kinase receptor function in vivo. Journal of Neuroscience, 29(3), 678-685.

Chai, N.-L. (2003). Effects of neurotrophins on gastrointestinal myoelectric activities of rats. World Journal of Gastroenterology, 9(8), 1874.

Chan, C. B., \& Ye, K. (2017). Sex differences in brain-derived neurotrophic factor signaling and functions. Journal of neuroscience research, 95(1-2), 328-335.

Chhatwal, J. P., Stanek-Rattiner, L., Davis, M., \& Ressler, K. J. (2006). Amygdala BDNF signaling is required for consolidation but not encoding of extinction. Nature neuroscience, 9(7), 870-872.

Choi, D. C., Gourley, S. L., \& Ressler, K. J. (2012). Prelimbic BDNF and TrkB signaling regulates consolidation of both appetitive and aversive emotional learning. Translational psychiatry, 2(12), e205-e205.

Clapp, M., Aurora, N., Herrera, L., Bhatia, M., Wilen, E., \& Wakefield, S. (2017). Gut microbiota's effect on mental health: the gut-brain axis. Clinics and Practice, 7(4).

Collins, S. M., Kassam, Z., \& Bercik, P. (2013). The adoptive transfer of behavioral phenotype via the intestinal microbiota: experimental evidence and clinical implications. Current opinion in microbiology, 16(3), 240-245.

Collins, S. M., Surette, M., \& Bercik, P. (2012). The interplay between the intestinal microbiota and the brain. In Nature Reviews Microbiology (Vol. 10, Issue 11, pp. 735742).

Cuijpers, P., Geraedts, A. S., Van Oppen, P., Andersson, G., Markowitz, J. C., \& Van Straten, A. (2011). Interpersonal psychotherapy for depression: A meta-analysis. In American Journal of Psychiatry (Vol. 168, Issue 6, pp. 581-592).

De Zwart, P. L., Jeronimus, B. F., \& De Jonge, P. (2019). Empirical evidence for definitions of episode, remission, recovery, relapse and recurrence in depression: A systematic review. Epidemiology and Psychiatric Sciences, 28(5), 544-562.

Deinhardt, K., \& Chao, M. V. (2014). Trk receptors. Handbook of Experimental Pharmacology, 220, 103-119. https://doi.org/10.1007/978-3-642-45106-5_5

Desbonnet, L., Garrett, L., Clarke, G., Bienenstock, J., \& Dinan, T. G. (2008). The probiotic Bifidobacteria infantis: an assessment of potential antidepressant properties in the rat. Journal of psychiatric research, 43(2), 164-174.

Detke, M. J., Wieland, S., \& Lucki, I. (1995). Blockade of the antidepressant-like effects of 8OH-DPAT, buspirone and desipramine in the rat forced swim test by 5HT1A receptor antagonists. Psychopharmacology, 119(1), 47-54. 
Dinel, A. L., Guinobert, I., Lucas, C., Blondeau, C., Bardot, V., Ripoche, I., ... \& Joffre, C. (2019). Reduction of acute mild stress corticosterone response and changes in stressresponsive gene expression in male Balb/c mice after repeated administration of a Rhodiola rosea L. root extract. Food science \& nutrition, 7(11), 3827-3841.

Donohue, H. S., Gabbott, P. L. A., Davies, H. A., Rodríguez, J. J., Cordero, M. I., Sandi, C., Medvedev, N. I., Popov, V. I., Colyer, F. M., Peddie, C. J., \& Stewart, M. G. (2006). Chronic restraint stress induces changes in synapse morphology in stratum lacunosummoleculare CA1 rat hippocampus: A stereological and three-dimensional ultrastructural study. Neuroscience, 140(2), 597-606.

Ernst, C., Deleva, V., Deng, X., Sequeira, A., Pomarenski, A., Klempan, T., Ernst, N., Quirion, R., Gratton, A., Szyf, M., \& Turecki, G. (2009). Alternative Splicing, Methylation State, and Expression Profile of Tropomyosin-Related Kinase B in the Frontal Cortex of Suicide Completers. Archives of General Psychiatry, 66(1), 22.

Etkin, A., \& Wager, T. D. (2007). Functional neuroimaging of anxiety: a meta-analysis of emotional processing in PTSD, social anxiety disorder, and specific phobia. American Journal of Psychiatry, 164(10), 1476-1488.

Forsythe, P., Bienenstock, J., \& Kunze, W. A. (2014). Vagal pathways for microbiome-braingut axis communication. Advances in Experimental Medicine and Biology, 817, 115-133.

Foster, J. A., \& Neufeld, K. A. M. (2013). Gut-brain axis: how the microbiome influences anxiety and depression. Trends in neurosciences, 36(5), 305-312.

Gałecki, P., Mossakowska-Wójcik, J., \& Talarowska, M. (2018). The anti-inflammatory mechanism of antidepressants-SSRIs, SNRIs. Progress in Neuro-Psychopharmacology and Biological Psychiatry, 80, 291-294.

Garcia, L. S. B., Comim, C. M., Valvassori, S. S., Réus, G. Z., Barbosa, L. M., Andreazza, A. C., Stertz, L., Fries, G. R., Gavioli, E. C., Kapczinski, F., \& Quevedo, J. (2008). Acute administration of ketamine induces antidepressant-like effects in the forced swimming test and increases BDNF levels in the rat hippocampus. Progress in NeuroPsychopharmacology and Biological Psychiatry, 32(1), 140-144.

Gideons, E. S., Kavalali, E. T., Monteggia, L. M., \& Huganir, R. L. (n.d.). Mechanisms underlying differential effectiveness of memantine and ketamine in rapid antidepressant responses.

Gourley, S. L., Kedves, A. T., Olausson, P., \& Taylor, J. R. (2009). A History of Corticosterone Exposure Regulates Fear Extinction and Cortical NR2B, GluR2/3, and BDNF. Neuropsychopharmacology, 34(3), 707-716.

Green, C. R., Corsi-Travali, S., \& Neumeister, A. (2013). The Role of BDNF-TrkB Signaling in the Pathogenesis of PTSD. Journal of Depression \& Anxiety, 2013(S4). 
Greenberg, M. E., Xu, B., Lu, B., \& Hempstead, B. L. (2009). New insights in the biology of BDNF synthesis and release: implications in CNS function. The Journal of Neuroscience: The Official Journal of the Society for Neuroscience, 29(41), 12764-12767.

Grider, J. R., Piland, B. E., Gulick, M. A., \& Qiao, L. Y. (2006). Brain-derived neurotrophic factor augments peristalsis by augmenting 5 - $\mathrm{HT}$ and calcitonin gene-related peptide release. Gastroenterology, 130(3), 771-780.

Hashimoto, K. (2010). Brain-derived neurotrophic factor as a biomarker for mood disorders: An historical overview and future directions. Psychiatry and Clinical Neurosciences, 64(4), 341-357.

He, X.-P., Kotloski, R., Nef, S., Luikart, B. W., Parada, L. F., \& McNamara, J. O. (2004). Conditional Deletion of TrkB but Not BDNF Prevents Epileptogenesis in the Kindling Model. Neuron, 43(1), 31-42.

Heijtz, R. D., Wang, S., Anuar, F., Qian, Y., Björkholm, B., Samuelsson, A., Hibberd, M. L., Forssberg, H., \& Pettersson, S. (2011). Normal gut microbiota modulates brain development and behavior. Proceedings of the National Academy of Sciences of the United States of America, 108(7), 3047-3052.

Heldt, S. A., \& Ressler, K. J. (2007). Training-induced changes in the expression of GABAAassociated genes in the amygdala after the acquisition and extinction of Pavlovian fear. European Journal of Neuroscience, 26(12), 3631-3644.

Hen, R., \& Nautiyal, K. M. (2017). Serotonin receptors in depression: From A to B. In F1000Research (Vol. 6). Faculty of 1000 Ltd.

Hess, N. J., Jiang, S., Li, X., Guan, Y., \& Tapping, R. I. (2017). TLR10 is a B cell intrinsic suppressor of adaptive immune responses. The Journal of Immunology, 198(2), 699707.

Hill, K. T., Warren, M., \& Roth, T. L. (2014). The influence of infant-caregiver experiences on amygdala Bdnf, OXTr, and NPY expression in developing and adult male and female rats. Behavioural brain research, 272, 175-180.

Holt, L. M., Hernandez, R. D., Pacheco, N. L., Torres Ceja, B., Hossain, M., \& Olsen, M. L. (2019). Astrocyte morphogenesis is dependent on BDNF signaling via astrocytic TrkB.T1. ELife, 8.

Hönemann Marienhospital, C. (2001). Modulation of NMDA Receptor Function by Ketamine and Magnesium: Part I Patient Blood Management und ,Atemgasklimatisierung und imhalative Sedierung mit der Anaconda View project Lung protective Ventilation View project. 
Janke, K. L., Cominski, T. P., Kuzhikandathil, E. V, Servatius, R. J., \& Pang, K. C. H. (2015). Investigating the Role of Hippocampal BDNF in Anxiety Vulnerability Using Classical Eyeblink Conditioning. Frontiers in Psychiatry, 6, 106.

Jiang, H., Ling, Z., Zhang, Y., Mao, H., Ma, Z., Yin, Y., Wang, W., Tang, W., Tan, Z., Shi, J., Li, L., \& Ruan, B. (2015). Altered fecal microbiota composition in patients with major depressive disorder. Brain, Behavior, and Immunity, 48, 186-194.

Kafitz, K. W., Rose, C. R., Thoenen, H., \& Konnerth, A. (1999). Neurotrophin-evoked rapid excitation through TrkB receptors. Nature, 401(6756), 918-921.

Kelly, J. R., Kennedy, P. J., Cryan, J. F., Dinan, T. G., Clarke, G., \& Hyland, N. P. (2015). Breaking down the barriers: The gut microbiome, intestinal permeability and stress-related psychiatric disorders. In Frontiers in Cellular Neuroscience (Vol. 9, Issue OCT). Frontiers Media S.A.

Kennett, G. A., Dourish, C. T., \& Curzon, G. (1987). Antidepressant-like action of 5-HT 1A agonists and conventional antidepressants in an animal model of depression. European Journal of Pharmacology, 134(3), 265-274.

Khanna, S., \& Tosh, P. K. (2014). A clinician's primer on the role of the microbiome in human health and disease. In Mayo Clinic Proceedings (Vol. 89, Issue 1, pp. 107-114). Elsevier Ltd.

Khubchandani, J., Brey, R., Kotecki, J., Kleinfelder, J. A., \& Anderson, J. (2016). The Psychometric Properties of PHQ-4 Depression and Anxiety Screening Scale Among College Students. Archives of Psychiatric Nursing, 30(4), 457-462.

Klimek, V., Stockmeier, C., Overholser, J., Meltzer, H. Y., Kalka, S., Dilley, G., \& Ordway, G. A. (1997). Reduced levels of norepinephrine transporters in the locus coeruleus in major depression. Journal of Neuroscience, 17(21), 8451-8458.

Kovalchuk, Y., Hanse, E., Kafitz, K. W., \& Konnerth, A. (2002). Postsynaptic induction of BDNF-mediated long-term potentiation. Science, 295(5560), 1729-1734.

Kozlovsky, N., Kaplan, Z., Zohar, J., Matar, M. A., Shimon, H., \& Cohen, H. (2008). Protein synthesis inhibition before or after stress exposure results in divergent endocrine and BDNF responses disassociated from behavioral responses. Depression and Anxiety, 25(5), E24-E34.

Kramár, E. A., Chen, L. Y., Lauterborn, J. C., Simmons, D. A., Gall, C. M., \& Lynch, G. (2012). BDNF upregulation rescues synaptic plasticity in middle-aged ovariectomized rats. Neurobiology of Aging, 33(4), 708-719. 
Laasonen-Balk, T., Kuikka, J., Viinamäki, H., Husso-Saastamoinen, M., Lehtonen, J., \& Tiihonen, J. (1999). Striatal dopamine transporter density in major depression. Psychopharmacology, 144(3), 282-285.

Leconte, C., Bihel, E., Lepelletier, F.-X., Bouët, V., Saulnier, R., Petit, E., Boulouard, M., Bernaudin, M., \& Schumann-Bard, P. (2011). Comparison of the effects of erythropoietin and its carbamylated derivative on behaviour and hippocampal neurogenesis in mice. Neuropharmacology, 60(2-3), 354-364.

Lenze, E. J., Mulsant, B. H., Shear, M. K., Alexopoulos, G. S., Frank, E., \& Reynolds, C. F. (2001). Comorbidity of depression and anxiety disorders in later life. In Depression and Anxiety (Vol. 14, Issue 2, pp. 86-93). John Wiley \& Sons, Ltd.

Levy, M. J. F., Boulle, F., Steinbusch, H. W., van den Hove, D. L. A., Kenis, G., \& Lanfumey, L. (2018). Neurotrophic factors and neuroplasticity pathways in the pathophysiology and treatment of depression. In Psychopharmacology (Vol. 235, Issue 8, pp. 21952220). Springer Verlag.

Liu, X., Zhu, Z., Kalyani, M., Janik, J. M., \& Shi, H. (2014). Effects of energy status and diet on Bdnf expression in the ventromedial hypothalamus of male and female rats. Physiology \& behavior, 130, 99-107.

Lonsdorf, T. B., Weike, A. I., Golkar, A., Schalling, M., Hamm, A. O., \& Öhman, A. (2010). Amygdala-dependent fear conditioning in humans is modulated by the BDNFval66met polymorphism. Behavioral neuroscience, 124(1), 9.

Lyte, M. (2011). Probiotics function mechanistically as delivery vehicles for neuroactive compounds: microbial endocrinology in the design and use of probiotics. Bioessays, 33(8), 574-581.

Ma, C., Cheng, F., Wang, X., Zhai, C., Yue, W., Lian, Y., \& Wang, Q. (2016). Erythropoietin pathway: A potential target for the treatment of depression. In International Journal of Molecular Sciences (Vol. 17, Issue 5). MDPI AG.

Ma, X. C., Dang, Y. H., Jia, M., Ma, R., Wang, F., Wu, J., Gao, C. G., \& Hashimoto, K. (2013). LongLasting Antidepressant Action of Ketamine, but Not Glycogen Synthase Kinase-3 Inhibitor SB216763, in the Chronic Mild Stress Model of Mice. PLoS ONE, 8(2).

Mahan, A. L., \& Ressler, K. J. (2012). Fear conditioning, synaptic plasticity and the amygdala: implications for posttraumatic stress disorder. Trends in neurosciences, 35(1), 24-35.

Mann, J. J., Stanley, M., McBride, P. A., \& McEwen, B. S. (1986). Increased Serotonin2 and $\beta$ Adrenergic Receptor Binding in the Frontal Cortices of Suicide Victims. Archives of General Psychiatry, 43(10), 954-959.

Maqsood, R., \& Stone, T. W. (2016). The gut-brain axis, BDNF, NMDA and CNS disorders. Neurochemical research, 41(11), 2819-2835. 
Martinowich, K., Manji, H., \& Lu, B. (2007). New insights into BDNF function in depression and anxiety. Nature neuroscience, 10(9), 1089-1093.

Matyas, J. J., O’Driscoll, C. M., Yu, L., Coll-Miro, M., Daugherty, S., Renn, C. L., Faden, A. I., Dorsey, S. G., \& Wu, J. (2017). Truncated TrkB.T1-Mediated Astrocyte Dysfunction Contributes to Impaired Motor Function and Neuropathic Pain after Spinal Cord Injury. The Journal of Neuroscience : The Official Journal of the Society for Neuroscience, 37(14), 3956-3971.

McLean, C. P., Asnaani, A., Litz, B. T., \& Hofmann, S. G. (2011). Gender differences in anxiety disorders: Prevalence, course of illness, comorbidity and burden of illness. Journal of Psychiatric Research, 45(8), 1027-1035.

McVey Neufeld, K. A., Kay, S., \& Bienenstock, J. (2018). Mouse strain affects behavioral and neuroendocrine stress responses following administration of probiotic Lactobacillus rhamnosus JB-1 or traditional antidepressant fluoxetine. Frontiers in neuroscience, 12, 294.

Meeker, R. B., \& Williams, K. S. (2015). The p75 neurotrophin receptor: At the crossroad of neural repair and death. Neural Regeneration Research, 10(5), 721-725.

Mestas, J., \& Hughes, C. C. (2004). Of mice and not men: differences between mouse and human immunology. The Journal of Immunology, 172(5), 2731-2738.

Miskowiak, K., Inkster, B., Selvaraj, S., Wise, R., Goodwin, G. M., \& Harmer, C. J. (2008). Erythropoietin improves mood and modulates the cognitive and neural processing of emotion 3 days post administration. Neuropsychopharmacology, 33(3), 611-618.

Moret, C., \& Briley, M. (2011). The importance of norepinephrine in depression. Neuropsychiatric Disease and Treatment, 7(SUPPL.), 9-13.

Mou, L., Heldt, S. A., \& Ressler, K. J. (2011). Rapid brain-derived neurotrophic factordependent sequestration of amygdala and hippocampal GABAA receptors via different tyrosine receptor kinase B-mediated phosphorylation pathways. Neuroscience, 176, 72-85.

Musumeci, G., \& Minichiello, L. (2011). BDNF-TrkB signalling in fear learning: from genetics to neural networks. Reviews in the Neurosciences, 22(3), 303-315.

Nardone, G., \& Compare, D. (2014). The psyche and gastric functions. Digestive Diseases, $32(3), 206-212$.

Nieuwsma, J. A., Trivedi, R. B., McDuffie, J., Kronish, I., Benjamin, D., \& Williams, J. W. (2012). Brief psychotherapy for depression: A systematic review and meta-analysis. International Journal of Psychiatry in Medicine, 43(2), 129-151. 
Ninan, I. (2014). Synaptic regulation of affective behaviors; role of BDNF. Neuropharmacology, 76 Pt C(0 0), 684-695.

Nosyreva, E., Szabla, K., Autry, A. E., Ryazanov, A. G., Monteggia, L. M., \& Kavalali, E. T. (2013). Acute Suppression of Spontaneous Neurotransmission Drives Synaptic Potentiation. Journal of Neuroscience, 33(16), 6990-7002.

Numakawa, T., Odaka, H., \& Adachi, N. (2018). Actions of Brain-Derived Neurotrophin Factor in the Neurogenesis and Neuronal Function, and Its Involvement in the Pathophysiology of Brain Diseases. International Journal of Molecular Sciences, 19(11).

Osadchiy, V., Martin, C. R., \& Mayer, E. A. (2019). The gut-brain axis and the microbiome: mechanisms and clinical implications. Clinical Gastroenterology and Hepatology, 17(2), 322-332.

Osborn, M., Rustom, N., Clarke, M., Litteljohn, D., Rudyk, C., Anisman, H., \& Hayley, S. (2013). Antidepressant-Like Effects of Erythropoietin: A Focus on Behavioural and Hippocampal Processes. PLoS ONE, 8(9).

Ou, L. C., \& Gean, P. W. (2006). Regulation of amygdala-dependent learning by brainderived neurotrophic factor is mediated by extracellular signal-regulated kinase and phosphatidylinositol-3-kinase. Neuropsychopharmacology, 31(2), 287-296.

Pandey, G. N., Ren, X., Rizavi, H. S., Conley, R. R., Roberts, R. C., \& Dwivedi, Y. (2008). Brainderived neurotrophic factor and tyrosine kinase $\mathrm{B}$ receptor signalling in post-mortem brain of teenage suicide victims. The International Journal of Neuropsychopharmacology, 11(08), 1047.

Pang, P. T., Teng, H. K., Zaitsev, E., Woo, N. T., Sakata, K., Zhen, S., Teng, K. K., Yung, W.-H., Hempstead, B. L., \& Lu, B. (2004). Cleavage of proBDNF by tPA/plasmin is essential for long-term hippocampal plasticity. Science (New York, N.Y.), 306(5695), 487-491.

Papakostas, G. I., Fava, M., \& Thase, M. E. (2008). Treatment of SSRI-Resistant Depression: A Meta-Analysis Comparing Within- Versus Across-Class Switches. Biological Psychiatry, 63(7), 699-704.

Park, A. J., Collins, J., Blennerhassett, P. A., Ghia, J. E., Verdu, E. F., Bercik, P., \& Collins, S. M. (2013). Altered colonic function and microbiota profile in a mouse model of chronic depression. Neurogastroenterology \& Motility, 25(9), 733-e575.

Pehrson, A. L., \& Sanchez, C. (2014). Serotonergic modulation of glutamate neurotransmission as a strategy for treating depression and cognitive dysfunction. CNS Spectrums, 19(2), 121-133. 
Poulter, M. O., Du, L., Zhurov, V., Merali, Z., \& Anisman, H. (2010). Plasticity of the GABAA receptor subunit cassette in response to stressors in reactive versus resilient mice. Neuroscience, 165(4), 1039-1051.

Price, R. B., Shungu, D. C., Mao, X., Nestadt, P., Kelly, C., Collins, K. A., Murrough, J. W., Charney, D. S., \& Mathew, S. J. (2009). Amino Acid Neurotransmitters Assessed by Proton Magnetic Resonance Spectroscopy: Relationship to Treatment Resistance in Major Depressive Disorder. Biological Psychiatry, 65(9), 792-800.

Prickaerts, J., \& Steckler, T. (2005). Effects of glucocorticoids on emotion and cognitive processes in animals. In Techniques in the Behavioral and Neural Sciences (Vol. 15, pp. 359-385). Elsevier.

Rattiner, L. M., Davis, M., \& Ressler, K. J. (2005). Brain-derived neurotrophic factor in amygdala-dependent learning. The Neuroscientist, 11(4), 323-333.

Rattiner, L. M., Davis, M., French, C. T., \& Ressler, K. J. (2004). Brain-derived neurotrophic factor and tyrosine kinase receptor B involvement in amygdala-dependent fear conditioning. Journal of Neuroscience, 24(20), 4796-4806.

Razavi, S., Nazem, G., Mardani, M., Esfandiari, E., Salehi, H., \& Esfahani, S. H. Z. (2015). Neurotrophic factors and their effects in the treatment of multiple sclerosis. Advanced Biomedical Research, 4, 53.

Rizos, E. N., Papathanasiou, M., Michalopoulou, P. G., Mazioti, A., Douzenis, A., Kastania, A., Nikolaidou, P., Laskos, E., Vasilopoulou, K., \& Lykouras, L. (2011). Association of serum BDNF levels with hippocampal volumes in first psychotic episode drug-naive schizophrenic patients. Schizophrenia Research, 129(2-3), 201-204.

Rogers, G. B., Keating, D. J., Young, R. L., Wong, M. L., Licinio, J., \& Wesselingh, S. (2016). From gut dysbiosis to altered brain function and mental illness: Mechanisms and pathways. In Molecular Psychiatry (Vol. 21, Issue 6, pp. 738-748). Nature Publishing Group.

Rose, C. R., Blum, R., Pichler, B., Lepier, A., Kafitz, K. W., \& Konnerth, A. (2003). Truncated TrkB-T1 mediates neurotrophin-evoked calcium signalling in glia cells. Nature, 426(6962), 74-78.

Sakuragi, S., Tominaga-Yoshino, K., \& Ogura, A. (2013). Involvement of TrkB- and p75(NTR)-signaling pathways in two contrasting forms of long-lasting synaptic plasticity. Scientific reports, 3, 3185. https://doi.org/10.1038/srep03185

Savignac, H. M., Kiely, B., Dinan, T. G., \& Cryan, J. F. (2014). Bifidobacteria exert strainspecific effects on stress-related behavior and physiology in BALB/c mice. Neurogastroenterology and Motility, 26(11), 1615-1627. 
Schafe, G. E., Atkins, C. M., Swank, M. W., Bauer, E. P., Sweatt, J. D., \& Ledoux, J. E. (2000). Activation of ERK/MAP kinase in the amygdala is required for memory consolidation of Pavlovian fear conditioning. Journal of Neuroscience, 20(21), 8177-8187.

Schwartz, J., Murrough, J. W., \& Iosifescu, D. V. (2016). Ketamine for treatment-resistant depression: Recent developments and clinical applications. In Evidence-Based Mental Health (Vol. 19, Issue 2, pp. 35-38). BMJ Publishing Group.

Singh, J. B., Fedgchin, M., Daly, E. J., De Boer, P., Cooper, K., Lim, P., Pinter, C., Murrough, J. W., Sanacora, G., Shelton, R. C., Kurian, B., Winokur, A., Fava, M., Manji, H., Drevets, W. C., \& Van Nueten, L. (2016). A double-blind, randomized, placebo-controlled, dosefrequency study of intravenous ketamine in patients with treatment-resistant depression. American Journal of Psychiatry, 173(8), 816-826.

Singh, M., Meyer, E. M., \& Simpkins, J. W. (1995). The effect of ovariectomy and estradiol replacement on brain-derived neurotrophic factor messenger ribonucleic acid expression in cortical and hippocampal brain regions of female Sprague-Dawley rats. Endocrinology, 136(5), 2320-2324.

Sitges, M., Gómez, C. D., \& Aldana, B. I. (2014). Sertraline Reduces IL-1 $\beta$ and TNF- $\alpha$ mRNA Expression and Overcomes Their Rise Induced by Seizures in the Rat Hippocampus. PLoS ONE, 9(11), e111665.

Snigdha, S., Neill, J. C., McLean, S. L., Shemar, G. K., Cruise, L., Shahid, M., \& Henry, B. (2011). Phencyclidine (PCP)-induced disruption in cognitive performance is gender-specific and associated with a reduction in brain-derived neurotrophic factor (BDNF) in specific regions of the female rat brain. Journal of molecular neuroscience, 43(3), 337-345.

Soetanto, A., Wilson, R. S., Talbot, K., Un, A., Schneider, J. A., Sobiesk, M., Kelly, J., Leurgans, S., Bennett, D. A., \& Arnold, S. E. (2010). Association of Anxiety and Depression with Microtubule-Associated Protein 2- and Synaptopodin-Immunolabeled Dendrite and Spine Densities in Hippocampal CA3 of Older Humans. Archives of General Psychiatry, $67(5), 448$.

Steinkamp, M., Schulte, N., Spaniol, U., Pflüger, C., Hartmann, C., Kirsch, J., \& von Boyen, G. (2012). Brain derived neurotrophic factor inhibits apoptosis in enteric glia during gut inflammation. Medical science monitor: international medical journal of experimental and clinical research, 18(4), BR117.

Stockmeier, C. A. (2003). Involvement of serotonin in depression: Evidence from postmortem and imaging studies of serotonin receptors and the serotonin transporter. Journal of Psychiatric Research, 37(5), 357-373. 
Sudo, N., Chida, Y., Aiba, Y., Sonoda, J., Oyama, N., Yu, X. N., Kubo, C., \& Koga, Y. (2004). Postnatal microbial colonization programs the hypothalamic-pituitary-adrenal system for stress response in mice. Journal of Physiology, 558(1), 263-275.

Tao, X., Finkbeiner, S., Arnold, D. B., Shaywitz, A. J., \& Greenberg, M. E. (1998). Ca2+ influx regulates BDNF transcription by a CREB family transcription factor-dependent mechanism. Neuron, 20(4), 709-726.

van Marle, H. J., Hermans, E. J., Qin, S., \& Fernández, G. (2009). From specificity to sensitivity: how acute stress affects amygdala processing of biologically salient stimuli. Biological psychiatry, 66(7), 649-655.

Vidaurre, O. G., Gascón, S., Deogracias, R., Sobrado, M., Cuadrado, E., Montaner, J., Rodríguez-Peña, A., \& Díaz-Guerra, M. (2012). Imbalance of neurotrophin receptor isoforms TrkB-FL/TrkB-T1 induces neuronal death in excitotoxicity. Cell Death and Disease, 3(1), e256-e256.

Vinberg, M., Miskowiak, K., Hoejman, P., Pedersen, M., \& Kessing, L. V. (2015). The effect of recombinant erythropoietin on plasma brain derived neurotrophic factor levels in patients with affective disorders: A randomised controlled study. PLoS ONE, 10(5).

Viviani, B., Bartesaghi, S., Corsini, E., Villa, P., Ghezzi, P., Garau, A., Galli, C. L., \& Marinovich, M. (2005). Erythropoietin protects primary hippocampal neurons increasing the expression of brain-derived neurotrophic factor. Journal of Neurochemistry, 93(2), 412-421.

Vuong, H. E., Yano, J. M., Fung, T. C., \& Hsiao, E. Y. (2017). The Microbiome and Host Behavior. Annual Review of Neuroscience, 40(1), 21-49.

Vyas, A., Jadhav, S., \& Chattarji, S. (2006). Prolonged behavioral stress enhances synaptic connectivity in the basolateral amygdala. Neuroscience, 143(2), 387-393.

Walz, C., Jüngling, K., Lessmann, V., \& Gottmann, K. (2006). Presynaptic Plasticity in an Immature Neocortical Network Requires NMDA Receptor Activation and BDNF Release. Journal of Neurophysiology, 96(6), 3512-3516.

Wang, P., Chen, F. X., Du, C., Li, C. Q., Yu, Y. B., Zuo, X. L., \& Li, Y. Q. (2015). Increased production of BDNF in colonic epithelial cells induced by fecal supernatants from diarrheic IBS patients. Scientific Reports, 5(1), 1-9.

Winter, G., Hart, R. A., Charlesworth, R. P. G., \& Sharpley, C. F. (2018). Gut microbiome and depression: what we know and what we need to know. Rev. Neurosci, 29(6), 629-643.

Wong, M. L., Inserra, A., Lewis, M. D., Mastronardi, C. A., Leong, L., Choo, J., Kentish, S., Xie, P., Morrison, M., Wesselingh, S. L., Rogers, G. B., \& Licinio, J. (2016). Inflammasome signaling affects anxiety- and depressive-like behavior and gut microbiome composition. Molecular Psychiatry, 21(6), 797-805. 
Woo, N. H., Teng, H. K., Siao, C.-J., Chiaruttini, C., Pang, P. T., Milner, T. A., Hempstead, B. L., \& Lu, B. (2005). Activation of p75NTR by proBDNF facilitates hippocampal long-term depression. Nature Neuroscience, 8(8), 1069-1077.

Wu, Y. C., Hill, R. A., Klug, M., \& van den Buuse, M. (2012). Sex-specific and region-specific changes in BDNF-TrkB signalling in the hippocampus of 5-HT1A receptor and BDNF single and double mutant mice. Brain research, 1452, 10-17.

Yamada, J., \& Jinno, S. (2019). Potential link between antidepressant-like effects of ketamine and promotion of adult neurogenesis in the ventral hippocampus of mice. Neuropharmacology, 158.

Yang, J.-J. (2015). Regulation of glutamate transporter 1 via BDNF-TrkB signaling plays a role in the anti-apoptotic and antidepressant effects of ketamine in chronic unpredictable stress model of dep. Article in Psychopharmacology.

Yang, R. J., Mozhui, K., Karlsson, R. M., Cameron, H. A., Williams, R. W., \& Holmes, A. (2008). Variation in mouse basolateral amygdala volume is associated with differences in stress reactivity and fear learning. Neuropsychopharmacology, 33(11), 2595-2604.

Yee, B. K., Zhu, S. W., Mohammed, A. H., \& Feldon, J. (2007). Levels of neurotrophic factors in the hippocampus and amygdala correlate with anxiety- and fear-related behaviour in C57BL6 mice. Journal of Neural Transmission, 114(4), 431-444.

Yoshii, A., \& Constantine-Paton, M. (2010). Postsynaptic BDNF-TrkB signaling in synapse maturation, plasticity, and disease. Developmental Neurobiology, NA-NA.

Yoshimura, R., Hori, H., Ikenouchi-Sugita, A., Umene-Nakano, W., Ueda, N., \& Nakamura, J. (2009). Higher plasma interleukin-6 (IL-6) level is associated with SSRI- or SNRIrefractory depression. Progress in Neuro-Psychopharmacology and Biological Psychiatry, 33(4), 722-726. https://doi.org/10.1016/j.pnpbp.2009.03.020

Zhang, G. F., Wang, J., Han, J. F., Guo, J., Xie, Z. M., Pan, W., Yang, J. J., \& Sun, K. J. (2016). Acute single dose of ketamine relieves mechanical allodynia and consequent depression-like behaviors in a rat model. Neuroscience Letters, 631, 7-12.

Zhang, Y., Chen, Y., \& Ma, L. (2018). Depression and cardiovascular disease in elderly: Current understanding. In Journal of Clinical Neuroscience (Vol. 47, pp. 1-5). Churchill Livingstone.

Zheng, P., Zeng, B., Zhou, C., Liu, M., Fang, Z., Xu, X., ... \& Zhang, X. (2016). Gut microbiome remodeling induces depressive-like behaviors through a pathway mediated by the host's metabolism. Molecular psychiatry, 21(6), 786-796.

Zhou, J., Zhang, H., Cohen, R. S., \& Pandey, S. C. (2005). Effects of estrogen treatment on expression of brain-derived neurotrophic factor and cAMP response element- 
binding protein expression and phosphorylation in rat amygdaloid and hippocampal structures. Neuroendocrinology, 81(5), 294-310. 